\title{
Secondary Analysis of Microarray Data Reveals Immune-Related Key Genes and Pathways in Chronic Spontaneous Urticaria
}

wenxing su

Second Affiliated Hospital of Soochow University

Biao Huang

First Affiliated Hospital of Soochow University

Yi Guan

Soochow University

Juanjuan Wang

Second Affiliated Hospital of Soochow University

\section{Yuqian Wei}

Second Affiliated Hospital of Soochow University

\section{Ying Zhao}

Second Affiliated Hospital of Soochow University

Jiang JI ( $\nabla_{\text {jijiang@suda.edu.cn ) }}$

Qingqing Jiao

First Affiliated Hospital of Soochow University

\section{Research article}

Keywords: Lupus Nephritis, anti-C1q antibody, anti-dsDNA antibody, anti-C3b antibody, biomarkers, Systemic Lupus Erythematosus

Posted Date: June 25th, 2020

DOI: https://doi.org/10.21203/rs.3.rs-35480/v1

License: (c) (1) This work is licensed under a Creative Commons Attribution 4.0 International License.

Read Full License 


\section{Abstract}

Background: Lupus Nephritis (LN) in patients with Systemic Lupus Erythematosus (SLE) is one of the most serious and prevalent manifestations. The procedure of renal biopsy is harmful and accompanied by potential hazards. Therefore, introducing reliable biomarkers to predict $L N$ is exceedingly worthwhile. In the current study, we compared the diagnostic values of circulating autoantibodies against dsDNA, C1q, C3b, SSA, SSB, and Sm alone or in combination to predict LN.

Methods: This study evaluated abovementioned autoantibodies in 40 healthy controls (HCs) and 95 SLE patients with different kidney involvements, including absent $(n=40)$, inactive $(n=20)$, and active $(n=35)$ LN using EIA method.

Result: The frequency and odds ratio of anti-dsDNA (71.4\%, OR=4.2), anti-C1q (62.9\%, OR= 5.1), and the simultaneous existence of anti-C1q and anti-dsDNA $(51.4 \%, \mathrm{OR}=6)$ antibodies were significantly higher in the active $\mathrm{LN}$ group compared with both inactive and absent LN groups. Moreover, the levels of anti-C1q and anti-dsDNA antibodies positively correlated with disease activity in patients with SLE. The prevalence of these autoantibodies was associated with the severity of LN biopsies.

Conclusion: These data suggest that anti-C1q and anti-dsDNA antibodies and also the simultaneous presence of them may be valuable diagnostic biomarkers for $L N$ prediction in patients with SLE.

\section{Background}

Urticaria is one of the most common clinical diseases in dermatology, mainly manifested as wheal, angioedema, or both. According to whether the course of disease exceeds 6 weeks, urticaria can be divided into acute and chronic conditions. Chronic spontaneous urticaria (CSU) refers to recurrent urticaria that lasts for more than 6 weeks without an identifiable trigger, accounting for about $25 \%$ of all urticaria, with an incidence rate of $0.5-1 \%$. In terms of the effects that cast on patients' life quality, urticaria can be put on a par with diabetes and coronary heart disease because of its repeated rashes and severe itching [1-3]. According to the EAACI/GA(2)LEN/EDF/WAO International Urticaria Guidelines (2018 Edition)[2], the treatment of this disease is still dominated by antihistamines. For intractable and refractory conditions, even further combined with hormones, immunomodulators or leukotriene receptor inhibitors, anticoagulants, and omalizumab, etc., the problem of relapse cannot be thoroughly solved. At present, the possible pathologic factors of CSU include Th1/Th2 cell imbalance, abnormal activation of immune cells (such as mast cells and basophils), autoimmunity, abnormal blood coagulation, and infection, whereas its exact pathogenesis remains unknown [4-6]. Therefore, in order to better control the clinical symptoms of CSU, revealing the molecular mechanism of its occurrence and development is urgently needed.

In recent years, bioinformatics analysis of gene expression profiles or other high-throughput data has played a key role in studying the pathogenesis of human diseases. However, single gene expression profiling analysis often has large errors. Therefore, in this study, we downloaded two datasets from the 
Gene Expression Omnibus (GEO) for the first time, including lesions of 16 CSU patients and normal epidermis of 13 healthy individuals. The common differentially expressed genes (DEGs) of the two data sets were screened and biological functions and pathway enrichment analysis were performed. Through protein-protein interaction (PPI) network analysis and GeneCards database, we identified four key genes, IL6, TLR4, ICAM1 and PTGS2. Besides, the module analysis showed that several key pathways are closely related to the occurrence and development of CSU and can be used as molecular targets for CSU treatment. In addition, we used xCell for the first time to analyze the difference in immune infiltration between CSU tissue and normal tissue in 64 immune and stromal cell types. It was found that there was a significant difference in the characteristics of immune infiltration between the CSU and the health control group.

\section{Results}

\subsection{Identification of DEGs in CSU}

After standardizing the microarray results, DEGs (292 in GSE57178 and 1221 in GSE72540) were identified (Fig. 1A and 1B). A total of 99 genes overlapped among the two datasets are shown in the Venn diagram (Fig. 1C), consisting of 92 upregulated genes and 7 downregulated genes. The heat map shows that these DEGs can basically distinguish CSU lesion samples from healthy control samples (Fig. 2).

\subsection{Analysis of the functional characteristics}

All gene expression information of CSU and healthy controls samples from two datasets was uploaded to GSEA, while the hallmark gene set database was used to analyze genes at the overall level of expression profile. The significantly enriched gene sets were set at a default cut-off as P-value $<0.05$ and FDR $<0.25$. The gene set enrichment analysis showed that four common gene sets were significantly enriched in CSU samples (Fig. 3), including TNF-a signaling via NF-KB, inflammatory response, IL-6/JAK/STAT3 signaling and interferon-gamma response. Enrichment analysis of BP showed that these common DEGs are mainly enriched in the inflammatory response and leukocyte migration. The top 10 biological processes based on P-value $<0.05$ were selected, and then a bar graph was drawn based on P-value and gene count (Fig. 4A and Table 2). Metascape visualized the interactive network of BP. The top five enriched terms are myeloid leukocyte activation, leukocyte migration, cytokine-mediated signaling pathway, positive regulation of defense response and cellular response to interferon-gamma (Fig. 4B).

A total of 99 DEGs were uploaded to Funrich for enrichment analysis of biological pathways. According to the results, DEGs were mainly enriched in IL6-mediated signaling events and formyl peptide receptors bind formyl peptides and many other ligands, as shown in Fig. 5. The top 20 terms of the pathway enrichment result, from two databases "KEGG pathway" and "Reactome", are shown in Fig. 6A and 6B (Tables 3 and 4).

\subsection{PPI network construction and module analysis}


The PPI network of DEGs with combined scores greater than 0.4 was generated by Cytoscape, which contained 87 nodes and 347 interaction pairs (Fig. 1D). Two modules were identified and created as subnetworks (Fig. 7A and 7C). In addition, the KEGG pathway enrichment analysis of genes included in each subnetwork was performed, which revealed that DEGs in the modules were mainly associated with TNF signaling pathway (involving PTGS2, IRF1, SOCS3, SELE, IL6 and ICAM1), NF-KB signaling pathway (involving PTGS2, CD14, CCL13, ICAM1 and TLR4) and Jak-STAT signaling pathway (involving IL6, MYC, OSMR, SOCS3 and PIM1) (Fig. 7B and 7D).

\subsection{Identification of key genes}

A total of 27 genes with degrees $\geq 10$ was identified as hub genes and 130 potential genes related to CSU (Relevance score $\geq 20$ ) were obtained from the GeneCards database. After intersecting, we obtained 4 key genes, namely IL6 (upregulated, degree $=42$, relevance score $=67.02$ ), TLR4 (upregulated, degree $=36$, relevance score $=36.12$ ), ICAM1 (upregulated, degree $=21$, relevance score $=22.93$ ), and PTGS2 (upregulated, degree $=21$, relevance score $=23.72)($ Fig. 8A and Table s1). A network of key genes and their co-expression genes was analyzed by GeneMANIA online platform. Analysis results of 4 key genes showed the complex PPI network with the Physical interactions of $67.64 \%$, Co-expression of $13.50 \%$, Predicted of $6.35 \%$, Co-localization of $6.17 \%$, Pathway of $4.35 \%$, Genetic interactions of $1.4 \%$ and Shared protein domains of $0.59 \%$ (Fig. 8B). Based on the DGIdb predictions of the key genes, we obtained 12 drug-gene interaction pairs, including four upregulated genes (IL6, TLR4, ICAM1, and PTGS2) and 12 drugs (FDA-listed + Immunotherapies), as shown in Fig. 8C.

\subsection{Immune and stromal cells deconvolution analyses}

Due to technical limitations, the status of immune infiltration in CSU has not been fully revealed, especially in subpopulations with low cell abundance. To determine the cell types that may be involved in CSU lesions, we used xCell, which uses a large amount of gene expression data to generate cell type enrichment scores. The GSE57178 and GSE72540 data sets have 8 types of immune cells that are significantly different, including neurons, dendritic cells (DC), megakaryocyte-erythroid progenitor (MEP), preadipocytes, mv endothelial cells, macrophages M1, mast cells, and Th2 cells (Fig. 9A). Compared with normal tissue, CSU tissue generally contained a higher proportion of DC, Th2 cells, mast cells, MEP, preadipocytes, and macrophages M1(Fig. 9B and 9C).

\subsection{Correlation analysis of key genes and infiltrating immune cells}

Correlation analysis showed that IL6 was positively correlated with activated Th2 cells $(r=0.504, p=$ 0.046), mv Endothelial cells $(r=0.525, p=0.037)$, and preadipocytes $(r=0.582, p=0.018)$; PTGS2 was positively correlated with neurons $(r=0.603, p=0.013)$, macrophages M1 $(r=0.618, p=0.011)$, and Th2 cells $(r=0.713, p=0.002)$; ICAM1 was positively correlated with Th2 cells $(r=0.506, p=0.045)$, mast cells $(r=0.532, p=0.034)$, MEP $(r=0.533, p=0.034)$, macrophages M1 $(r=0.541, p=0.03)$, mv Endothelial 
cells $(r=0.591, p=0.016)$, and preadipocytes $(r=0.727, p=0.001)$; TLR4 was positively correlated with mv Endothelial cells $(r=0.651, p=0.006)$, preadipocytes $(r=0.651, p=0.006)$, macrophages $M 1(r=0.683$, $p=0.004)$, and $\operatorname{MEP}(r=0.732, p=0.001)$ (Fig. 10).

\section{Discussion}

As an immune-mediated inflammatory disease, CSU is closely related to autoimmune process and systemic inflammatory response. The autoimmunity theory and Th1/Th2 cell imbalance hypothesis related to its pathogenesis have been discussed most in the past $[6,7]$. In order to better understand its pathogenesis, this article explores from the molecular level. In this study, through protein-protein interaction (PPI) network analysis and GeneCards database, we identified four key genes, including IL6, TLR4, ICAM1, and PTGS2. Through the enrichment analysis of the core modules, three signal pathways, TNF signaling pathway, NF-KB signaling pathway and Jak-STAT signaling pathway, were found to be closely related to the occurrence and development of CSU. Based on these genes and pathways involved in a variety of immune responses and chemotaxis of immune cells, we used the xCell to analyze the immune cell infiltration of CSU patients with lesions. Results showed that immune cell infiltration of CSU was significantly different from that of the health control group.

Dysregulation of TNF-a signaling pathway is an important feature and pathogenic factor of various diseases, including sepsis, cancer, autoimmune and inflammatory diseases[8]. Previous studies reported that the upregulated expression of TNF-a was found in skin tissue biopsy of patients with different types of urticaria [9]. In addition, the concentration of TNF- $a$ and its soluble receptor types 1 and 2 (sTNFR1 and sTNFR2, respectively) in serum of CSU patients increased significantly, suggesting that the activation of TNF-a signaling pathway is related to the development of CSU [10]. On the other hand, the significant effect of TNF-a inhibitors on refractory urticaria where other treatments were proved ineffective, also shows the importance of TNF-a signaling pathway in the development of CSU[11, 12]. However, control studies with larger scale and longer follow-up periods are needed to confirm the efficacy and safety of TNF-a inhibitors in the treatment of CSU patients.

The NF-KB signaling pathway plays an important role in regulating the survival and activation of $T$ and $B$ lymphocytes in the thymus, bone marrow, spleen, and periphery[13]. The dysregulation of NF-KB signal leads to its structural activation, which leads to autoimmunity and chronic inflammation. Many autoimmune diseases have been proved to be associated with dysregulation of NF-KB signaling, including type 1 diabetes, systemic lupus erythematosus, and rheumatoid arthritis[14]. TNF is a major inflammatory cytokine that activates NF-KB, with most of its inflammation mediated by TNF receptor 1 (TNFR1) $[15,16]$. The positive effect of neutralizing TNFR1-NF-KB signaling in autoimmune and inflammatory syndrome has been confirmed[17]. Our GSEA enrichment results showed that the TNF-a signaling via NF-KB of CSU patients in the two data sets was highly expressed, which supports the autoimmunity theory of CSU. 
The Jak/STAT3 signaling pathway, as a conduction pathway closely related to inflammatory reactions, is involved in the development of chronic inflammatory diseases such as atopic dermatitis and psoriasis. The Jak inhibitor JTE-052 has shown good efficacy in the treatment of chronic dermatitis induced by hapten in rats, and is expected to become a candidate drug for the treatment of chronic dermatitis [18]. Recent studies have shown that Jak/STAT3 signaling pathway is also involved in the pathogenesis of CSU. Luo et al. found that OSMR gene is highly expressed in skin lesions of CSU patients, which leads to the up-regulation of Jak/STAT3 signaling pathway related gene expression. In addition, OSMR gene silencing can significantly reduce the content of inflammatory factors, eosinophils, mRNA and protein expression of Jak/STAT3 signaling pathway related genes, promote cell proliferation and migration, and inhibit epithelial cell apoptosis to suppress CSU mouse model autoimmunity reaction [19]. Another study also found that IL9 and IL10 can promote the development of CSU by activating the Jak/STAT3 signaling pathway [20]. Interestingly, our GSEA enrichment results on two data sets showed high expression of IL6/Jak/STAT3 pathway in the CSU patient group. The abnormality of IL6/Jak/STAT3 signaling pathway is closely related to autoimmune diseases. IL-6 and its receptor IL-6R monoclonal antibody drugs have been approved for the treatment of rheumatoid arthritis and achieved good results[21, 22]. In addition, studies have confirmed that IL6/Jak/STAT3 signaling pathway is closely related to mast cell degranulation and allergic reactions[23]. Therefore, blocking IL6/Jak/STAT3 signaling pathway may be a new strategy for the treatment of refractory CSU.

IL6, a cytokine that plays an important role in inflammation and immune response, is involved in the development of various autoimmune and chronic inflammatory diseases, including rheumatoid arthritis (RA), systemic lupus erythematosus, Multiple sclerosis, adult Still's disease and psoriasis[24-26]. More and more evidences-the expression of IL6 in serum and skin lesion tissue of CSU patients significantly increased and its expression level can be significantly reduced after the symptoms are relieved, suggest that IL6 is also involved in the occurrence and development of CSU[27, 28]. IL6 mainly works in immune and inflammatory responses through two different pathways: one is that after binding to the low-affinity cell membrane IL6 receptor (IL6R), it interacts with the signal transduction component glycoprotein 130 ( gp130) to form a high-affinity complex that initiates intracellular signaling (classical receptor signaling pathway); the other is that IL6 binds to soluble IL6 receptor (sIL6R) and then forms a complex with gp130, resulting in a signal Transduction (trans signaling pathway)[29]. gp130 is commonly expressed in cells, but under normal circumstances, IL6R only exists on specific cell surfaces such as liver cells, neutrophils, monocytes, macrophages, and $T$ and $B$ lymphocytes. sIL6R is transported in body fluids and mediates IL 6 signal transduction of various gp130-only cells such as nerve cells, smooth muscle cells and endothelial cells[30]. In fact, many IL6 effects are mediated by the IL6/sIL6R/gp130 complex, especially in chronic inflammatory and autoimmune diseases[31]. Studies have confirmed that the increase of the plasma levels of IL6 and sIL6R in CSU patients and the increase of the serum C-reactive protein (CRP) concentration suggest the activation of IL6 trans signaling pathway, which may be accompanied by the activation of acute phase response and enhancement of disease activity[32]. Specifically, on the one hand, the IL6/sIL6R complex stimulates the synthesis of acute phase proteins (such as CRP) and promotes the synthesis and secretion of immunoglobulins by $B$ lymphocytes, which 
thereby promotes the production of autoantibodies; on the other hand, it can inhibit the differentiation of Th1 and Treg cells, promote the differentiation of Th2 and Th17 cells, and finally cause the imbalance of Th1/Th2 cells[24, 33]. Th2 cells can not only promote B cells to produce IgE, but also participate in the pathogenesis of allergic diseases by producing cytokines such as IL4, IL10, IL13[34], which is verified in the results of Reactome enrichment. In addition, IL6 may activate eosinophils, leading to the expression of tissue factor (TF). TF can promote the formation of thrombin, which in turn causes mast cells to subsequently degranulate, increasing vascular permeability[35].

PTGS2, also known as cyclooxygenase 2 (COX2), is a key enzyme in the biosynthesis of prostaglandin D2 (PGD2) involved in inflammation. The high expression of PTGS2 can promote large amount of PGD2 synthesis and aggravate the inflammatory response in CSU patients. Besides, IL6 classical signaling can also enhance the expression of COX2 induced by FcERI, which thereby enhances the production of IgEdependent PGD2 by human tissue-derived mast cells[36]. It is well known that endothelial dysfunction may increase vascular permeability, leading to a pro-inflammatory response. ICAM1, as a biomarker of endothelial dysfunction, is detected in the skin biopsy of CSU patients whose expression level was upregulated, reflecting the proinflammatory phenotype of its endothelium[37]. In addition, circulating soluble ICAM1 also plays a potential role in the pathogenesis of CSU, however, it is not parallel to disease activity, nor can it predict the efficacy of $\mathrm{H} 1$ antihistamine therapy[38]. TLR4, the earliest discovered Toll-like receptors (TLRs), can regulate the expression of various genes through NF-kB signaling after activation, like IL6, ICAM1, COX2, etc. At the same time, the massive production of Th2 cytokines will also lead to the imbalance of Th1/Th2 cells[39, 40], promoting the CSU to develop.

From the immune infiltration analysis, we found that CSU tissue generally contained a higher proportion of DC, Th2 cells, mast cells, MEP, preadipocytes, and macrophages M1. As we all know, type 1 allergy plays an important role in CSU. DC, as the main antigen presenting cell, transmits allergens to $B$ cells and activates them to generate plasma cells, which synthesizes and secretes $\operatorname{lgE}$. In addition, as previously mentioned, Th2 cells can help activate B cells to produce IgE, and also can further expand the inflammatory response by producing cytokines such as IL-4, IL-10, IL-13. As a key effector cell in the pathogenesis of CSU, mast cell can release inflammatory mediators such as histamine and PGD2 after being activated, resulting in increased permeability of vasculature and recruitment of inflammatory cells, further causing symptoms such as wheal, itching, and edema [41]. In addition, macrophage M1 can produce proinflammatory related factors, such as IL- 6 and TNF, and participate in the inflammatory response of CSU[42]. Our analysis results are basically consistent with the previous reports about CSU immune cell infiltration, which in turns proves the accuracy of our study. However, studies on MEP, preadipocytes, and CSU have not been reported, and this potential connection is worth further exploration. In addition, we analyzed the correlation between IL6, TLR4, ICAM1, and PTGS2 and immune cells, and found that IL6 was positively correlated with activated Th2 cells, mv Endothelial cells, and preadipocytes; PTGS2 was positively correlated with neurons, macrophages M1, and Th2 cells; ICAM1 was positively correlated with Th2 cells, mast cells, MEP, macrophages M1, mv Endothelial cells, and preadipocytes; TLR4 was positively correlated with mv Endothelial cells, preadipocytes, macrophages M1, and MEP. This indicates that these key genes also play an important role in the immune infiltration of CSU. However, the 
specific impact of these differentially expressed genes on the immune invasion of CSU lesions needs further study.

We acknowledged that the study has some certain limitations. First, the sample size we analyzed is relatively small. Second, this is a retrospective study and all the data are from publicly available databases. Third, results require further confirmation such as by vivo or vitro experiments. However, it is important that no one has done similar research on CSU before. Our results may provide new insights into the occurrence and development of CSU.

\section{Conclusions}

In summary, the purpose of this study was to identify DEGs that may be associated with pathogenesis of CSU. A total of 4 key genes have been identified, which can be used as a marker for CSU or as a drug therapy target. In addition, three signal pathways were found to be closely related to the occurrence and development of CSU: TNF signaling pathway, NF-KB signaling pathway and Jak-STAT signaling pathway. By combining a reliable deconvolution algorithm with large-scale genomic data, we found that there is a difference in immune infiltration between the CSU and the health control group. However, the relationship between key genes and immune infiltration and the biological functions of key genes and immune infiltration profiles in CSU need further study.

\section{Methods}

\subsection{Raw data collection}

GEO (http://www.ncbi.nlm.nih.gov/geo) is a gene expression database created by NCBI, which contains high-throughput gene expression data submitted by research institutes worldwide. Two microarray datasets (GSE57178[43] and GSE72540[44]) were downloaded from it. Table 1 shows the details of the two data sets. All patients showed severely active CSU (urticaria activity score (UAS)7 $\geq 11$ ) for at least 3 months, and standard dose antihistamine therapy was ineffective.

\subsection{Identification of DEGs}

Raw data of GSE57178 and GSE72540 datasets were read through the "affy" package, and the RMA algorithm was used for background correction and data normalization. The "limma" package was used to screen out DEGs. Probe sets without corresponding gene symbols or genes with more than one probe set were removed or averaged, respectively. $|\mathrm{LogFC}|>1$ and $\mathrm{P}$-value $<0.05$ were considered statistically significant.

\subsection{Enrichment analyses}

Gene set enrichment analysis (GSEA) refers to sorting genes according to the degree of differential expression from the two types of samples and then checking whether the preset gene set is enriched at the top or bottom of this sorting table[45]. GSEA can retain this key information without screening out 
differences, and then find out those functional gene sets that are not obviously different but have a same trend of genetic differences. The genetic information of all CSU and healthy control samples was uploaded to GSEA for further analysis. Annotation, visualization and integrated discovery database (DAVID; https://david.ncifcrf.gov/) (version 6.8) were used to analyze the DEGs of CSU and found a significantly enriched biological process (BP). In addition, Metascape (https://metascape.org/) was adopted to analyze the interaction network of enriched BP.

The functional enrichment analysis tool (Funrich)[46] was chosen to analyze the biological pathways of DEGs. The pathway enrichment analyses of DEGs were evaluated by KOBAS 3.0 (http://kobas.cbi.pku.edu.cn). Two databases, "KEGG pathway" and "Reactome", were for further analyses. Pathway analysis was conducted to find out which cellular pathways may be involved in the changes of DEGs. Therefore, the key pathways related to DEGs can be identified. P-value $<0.05$ was considered significant.

\subsection{PPI network construction and analysis of key modules}

Search Tool for the Retrieval of Interacting Genes (STRING; http://string-db.org) (version 10.0), which is an online database of known and predicted protein interactions, was applied to predict the PPI network of DEGs. Only interactions with a combined score $>0.4$ were considered statistically significant. Cytoscape (version 3.6.1, http://www.cytoscape.org) was used to visualize molecular interaction networks, with its CytoNCA plug-in analyzing the topological properties of nodes in the PPI network and setting parameters to no weight. By ranking the scores of each node, we obtained important nodes involved in protein interactions within the network. The Molecular Complex Detection (MCODE; version 1.5.1) of Cytoscape was applied to screen the most significant module in the PPI networks with MCODE scores $>5$, degree cut-off $=2$, node score cut-off $=0.2$, max depth $=100$ and k-score $=2$.

\subsection{Identification of genes of interest}

Considering that most networks were scale-free, the hub genes with degrees $\geq 10$ were chosen. In addition, we used GeneCards database (https://www.genecards.org/) to identify some other potential related genes of CSU (Relevance score $\geq 20$ ), and then intersect with hub genes to get the key genes. A network of the key genes and their co-expression genes was analyzed via GeneMANIA (http://www.genemania.org/). Besides, Drug-Gene Interaction database (DGIdb 2.0; http://www.dgidb.org/), which mines existing resources and generates assumptions about how genes are therapeutically targeted or prioritized for drug development, was adopted in the study to predict drugs based on the genes of interest. The parameters were set as: preset filters: FDA approved; Immunotherapies; all the default. All the drug-gene relationship pairs related to the key genes were predicted, and the network map was formed by Cytoscape.

\subsection{Immune and stromal cells deconvolution analyses}

xCell, a novel gene signature-based method, was used to infer 64 immune and stromal cell types with extensive in silico analyses and compared to cytometry immunophenotyping[47]. By applying xCell to the 
microarray data and Wilcoxon method for variance, the estimated proportion of immune and stromal cell types can be obtained for each renal sample. The cut-off values for the cell analyses were P-value $<0.05$. Cell types were categorized into lymphoid, myeloid, stromal, stem cells, and others. Venn diagrams were used to compare common cell types from different datasets.

\subsection{Correlation analysis of key genes and infiltrating immune cells}

Spearman correlation analysis was performed on key genes and infiltrating immune cells using the "ggstatsplot" software package, and the results were visualized using the "ggplot2" software package.

\section{Abbreviations}

Chronic spontaneous urticaria (CSU), Gene Expression Omnibus (GEO), differentially expressed genes (DEGs), protein-protein interaction (PPI), Drug-Gene Interaction database (DGIdb), interleukin 6 (IL6), toll like receptor 4 (TLR4), intercellular adhesion molecule 1 (ICAM1), prostaglandin-endoperoxide synthase 2 (PTGS2), urticaria activity score (UAS), fold-changes (FC), Gene set enrichment analysis (GSEA), biological processes (BP), dendritic cells (DC), megakaryocyte-erythroid progenitor (MEP), TNF receptor 1 (TNFR1), soluble IL6 receptor (sIL6R), C-reactive protein (CRP), tissue factor (TF), cyclooxygenase 2 (COX2), prostaglandin D2 (PGD2), Toll-like receptors (TLRs), lesional skin (LS), non-lesional skin (NL), normal skin (NS).

\section{Declarations}

\section{Acknowledgement}

Not applicable.

\section{Authors' contributions}

This article was done in collaboration with all the following authors. JQQ and JJ determined the research theme and formulated the main research plan. SWX, HB, and GY analyzed the data, explained the results, and wrote the manuscript. WJJ, WYQ and ZY helped collect data and references. All authors read and approved the final manuscript.

\section{Funding}

None.

\section{Availability of data and materials}

All data in this article comes from an open public database and is available for free.

\section{Ethical approval and consent to participate}


Since all materials for this study are from public databases, no ethics committee approval is required.

\section{Consent for publication}

All authors agree to publish this article.

\section{Competing Interests}

The authors have no conflicts of interest to declare.

\section{Author details}

1 Department of Dermatology, The Second Affiliated Hospital of Soochow University, Suzhou, Jiangsu, China. 5 Department of Medicine, Soochow University, Suzhou, Jiangsu, China.

\section{References}

1. Zuberbier T, Aberer W, Asero R, Bindslev-Jensen C, Brzoza Z, Canonica GW, Church MK, Ensina LF, Gimenez-Arnau A, Godse K, et al. The EAACl/GA(2) LEN/EDF/WAO Guideline for the definition, classification, diagnosis, and management of urticaria: the 2013 revision and update. Allergy. 2014;69(7):868-87.

2. Dressler C, Rosumeck S, Werner RN, Magerl M, Metz M, Maurer M, Nast A, Zuberbier T. Executive summary of the methods report for 'The EAACI/GA(2) LEN/EDF/WAO Guideline for the Definition, Classification, Diagnosis and Management of Urticaria. The 2017 Revision and Update'. Allergy. 2018;73(5):1145-6.

3. Wood RA, Khan DA, Lang DM, Fasano MB, Peden DB, Busse PJ, Carter MC, Demain JG, Dinakar C, Grayson $\mathrm{MH}$, et al. American Academy of Allergy, Asthma and Immunology response to the EAACI/GA(2) LEN/EDF/WAO guideline for the definition, classification, diagnosis, and management of Urticaria 2017 revision. Allergy. 2019;74(2):411-3.

4. Kaplan AP. Chronic Spontaneous Urticaria: Pathogenesis and Treatment Considerations. Allergy Asthma Immunol Res. 2017;9(6):477-82.

5. Saini SS. Chronic spontaneous urticaria: etiology and pathogenesis. Immunol Allergy Clin North Am. 2014;34(1):33-52.

6. Kolkhir P, Balakirski G, Merk HF, Olisova O, Maurer M. Chronic spontaneous urticaria and internal parasites-a systematic review. Allergy. 2016;71(3):308-22.

7. Bracken SJ, Abraham S, MacLeod AS. Autoimmune Theories of Chronic Spontaneous Urticaria. Front Immunol. 2019;10:627.

8. Chen G, Goeddel DV. TNF-R1 signaling: a beautiful pathway. Science. 2002;296(5573):1634-5.

9. Hermes B, Prochazka AK, Haas N, Jurgovsky K, Sticherling M, Henz BM. Upregulation of TNF-alpha and IL-3 expression in lesional and uninvolved skin in different types of urticaria. J Allergy Clin Immunol. 1999;103(2 Pt 1):307-14. 
10. Grzanka R, Damasiewicz-Bodzek A, Kasperska-Zajac A. Tumor necrosis factor-alpha and Fas/Fas ligand signaling pathways in chronic spontaneous urticaria. Allergy asthma clinical immunology: official journal of the Canadian Society of Allergy Clinical Immunology. 2019;15:15.

11. Wilson LH, Eliason MJ, Leiferman KM, Hull CM, Powell DL. Treatment of refractory chronic urticaria with tumor necrosis factor-alfa inhibitors. J Am Acad Dermatol. 2011;64(6):1221-2.

12. Sand FL, Thomsen SF. TNF-Alpha Inhibitors for Chronic Urticaria: Experience in 20 Patients. Journal of allergy. 2013;2013:130905.

13. Siebenlist U, Brown K, Claudio E. Control of lymphocyte development by nuclear factor-kappaB. Nature reviews Immunology. 2005;5(6):435-45.

14. Brown KD, Claudio E, Siebenlist U. The roles of the classical and alternative nuclear factor-kappaB pathways: potential implications for autoimmunity and rheumatoid arthritis. Arthritis research therapy. 2008;10(4):212.

15. Wertz IE. TNFR1-activated NF-KB signal transduction: regulation by the ubiquitin/proteasome system. Curr Opin Chem Biol. 2014;23:71-7.

16. Brenner $\mathrm{D}$, Blaser $\mathrm{H}$, Mak TW. Regulation of tumour necrosis factor signalling: live or let die. Nature reviews Immunology. 2015;15(6):362-74.

17. Kalliolias GD, Ivashkiv LB. TNF biology, pathogenic mechanisms and emerging therapeutic strategies. Nature reviews Rheumatology. 2016;12(1):49-62.

18. Tanimoto A, Shinozaki Y, Yamamoto Y, Katsuda Y, Taniai-Riya E, Toyoda K, Kakimoto K, Kimoto Y, Amano W, Konishi N, et al. A novel JAK inhibitor JTE-052 reduces skin inflammation and ameliorates chronic dermatitis in rodent models: Comparison with conventional therapeutic agents. Exp Dermatol. 2018;27(1):22-9.

19. Luo XY, Liu Q, Yang H, Tan Q, Gan LQ, Ren FL, Wang H. OSMR gene effect on the pathogenesis of chronic autoimmune Urticaria via the JAK/STAT3 pathway. Molecular medicine (Cambridge Mass). 2018;24(1):28.

20. Feng H, Feng J, Zhang Z, Xu Q, Hu M, Wu Y, Lu Y. Role of IL-9 and IL-10 in the pathogenesis of chronic spontaneous urticaria through the JAK/STAT signalling pathway. Cell biochemistry and function 2020.

21. Pelechas E, Voulgari PV, Drosos AA. Sirukumab: a promising therapy for rheumatoid arthritis. Expert Opin Biol Ther. 2017;17(6):755-63.

22. Scott LJ. Sarilumab: First Global Approval. Drugs. 2017;77(6):705-12.

23. Hox V, O'Connell MP, Lyons JJ, Sackstein P, Dimaggio T, Jones N, Nelson C, Boehm M, Holland SM, Freeman $\mathrm{AF}$, et al. Diminution of signal transducer and activator of transcription 3 signaling inhibits vascular permeability and anaphylaxis. J Allergy Clin Immunol. 2016;138(1):187-99.

24. Neurath MF, Finotto S. IL-6 signaling in autoimmunity, chronic inflammation and inflammationassociated cancer. Cytokine Growth Factor Rev. 2011;22(2):83-9. 
25. Tackey E, Lipsky PE, Illei GG. Rationale for interleukin-6 blockade in systemic lupus erythematosus. Lupus. 2004;13(5):339-43.

26. Tanaka T, Narazaki M, Kishimoto T. Therapeutic targeting of the interleukin- 6 receptor. Annu Rev Pharmacol Toxicol. 2012;52:199-219.

27. Kasperska-Zajac A, Sztylc J, Machura E, Jop G. Plasma IL-6 concentration correlates with clinical disease activity and serum C-reactive protein concentration in chronic urticaria patients. Clin Exp Allergy. 2011;41(10):1386-91.

28. de Montjoye L, Choteau M, Herman A, Hendrickx E, Chéou P, Baeck M, Dumoutier L. IL-6 and IL-1 $\beta$ expression is increased in autologous serum skin test of patients with chronic spontaneous urticaria. Allergy. 2019;74(12):2522-4.

29. Garbers C, Hermanns HM, Schaper F, Müller-Newen G, Grötzinger J, Rose-John S, Scheller J. Plasticity and cross-talk of interleukin 6-type cytokines. Cytokine Growth Factor Rev. 2012;23(3):85-97.

30. Dayer JM, Choy E. Therapeutic targets in rheumatoid arthritis: the interleukin-6 receptor. Rheumatology. 2010;49(1):15-24.

31. Chalaris A, Garbers C, Rabe B, Rose-John S, Scheller J. The soluble Interleukin 6 receptor: generation and role in inflammation and cancer. Eur J Cell Biol. 2011;90(6-7):484-94.

32. Kasperska-Zajac A, Grzanka A, Damasiewicz-Bodzek A. IL-6 Transsignaling in Patients with Chronic Spontaneous Urticaria. PloS one. 2015;10(12):e0145751.

33. Ataie-Kachoie P, Pourgholami MH, Morris DL. Inhibition of the IL-6 signaling pathway: a strategy to combat chronic inflammatory diseases and cancer. Cytokine Growth Factor Rev. 2013;24(2):163-73.

34. Romagnani S. The role of lymphocytes in allergic disease. J Allergy Clin Immunol. 2000;105(3):399408.

35. Tedeschi A, Kolkhir P, Asero R, Pogorelov D, Olisova O, Kochergin N, Cugno M. Chronic urticaria and coagulation: pathophysiological and clinical aspects. Allergy. 2014;69(6):683-91.

36. McHale C, Mohammed Z, Deppen J, Gomez G. Interleukin-6 potentiates FceRI-induced PGD(2) biosynthesis and induces VEGF from human in situ-matured skin mast cells. Biochimica et biophysica acta General subjects. 2018;1862(5):1069-78.

37. Caproni M, Volpi W, Macchia D, Giomi B, Manfredi M, Campi P, Cardinali C, D'Agata A, Fabbri P. Infiltrating cells and related cytokines in lesional skin of patients with chronic idiopathic urticaria and positive autologous serum skin test. Exp Dermatol. 2003;12(5):621-8.

38. Puxeddu I, Panza F, Pratesi F, Bartaloni D, Casigliani Rabl S, Rocchi V, Del Corso I, Migliorini P. CCL5/RANTES, sVCAM-1, and sICAM-1 in chronic spontaneous urticaria. Int Arch Allergy Immunol. 2013;162(4):330-4.

39. Chang H, Zhang QY, Lin Y, Cheng N, Zhang SQ. Correlation of TLR2 and TLR4 expressions in peripheral blood mononuclear cells to Th1- and Th2-type immune responses in children with henochschönlein purpura. Int J Clin Exp Med. 2015;8(8):13532-9. 
40. Sugitharini V, Shahana P, Prema A, Berla Thangam E. TLR2 and TLR4 co-activation utilizes distinct signaling pathways for the production of Th1/Th2/Th17 cytokines in neonatal immune cells. Cytokine. 2016;85:191-200.

41. Caproni M, Giomi B, Melani L, Volpi W, Antiga E, Torchia D, Fabbri P. Cellular infiltrate and related cytokines, chemokines, chemokine receptors and adhesion molecules in chronic autoimmune urticaria: comparison between spontaneous and autologous serum skin test induced wheal. Int $\mathrm{J}$ ImmunoPathol Pharmacol. 2006;19(3):507-15.

42. Murray PJ, Allen JE, Biswas SK, Fisher EA, Gilroy DW, Goerdt S, Gordon S, Hamilton JA, Ivashkiv LB, Lawrence T, et al. Macrophage activation and polarization: nomenclature and experimental guidelines. Immunity. 2014;41(1):14-20.

43. Patel OP, Giorno RC, Dibbern DA, Andrews KY, Durairaj S, Dreskin SC. Gene expression profiles in chronic idiopathic (spontaneous) urticaria. Allergy Rhinol (Providence). 2015;6(2):101-10.

44. Giménez-Arnau A, Curto-Barredo L, Nonell L, Puigdecanet E, Yelamos J, Gimeno R, Rüberg S, Santamaria-Babi L, Pujol RM. Transcriptome analysis of severely active chronic spontaneous urticaria shows an overall immunological skin involvement. Allergy. 2017;72(11):1778-90.

45. Subramanian A, Tamayo P, Mootha VK, Mukherjee S, Ebert BL, Gillette MA, Paulovich A, Pomeroy SL, Golub TR, Lander ES, et al. Gene set enrichment analysis: a knowledge-based approach for interpreting genome-wide expression profiles. Proc Natl Acad Sci USA. 2005;102(43):15545-50.

46. Pathan M, Keerthikumar S, Ang C-S, Gangoda L, Quek CYJ, Williamson NA, Mouradov D, Sieber OM, Simpson RJ, Salim A, et al. FunRich: An open access standalone functional enrichment and interaction network analysis tool. Proteomics. 2015;15(15):2597-601.

47. Aran D, Hu Z, Butte AJ. xCell: digitally portraying the tissue cellular heterogeneity landscape. Genome biology. 2017;18(1):220.

\section{Tables}

Table 1. Details of the GEO datasets. Lesional skin (LS), non-lesional skin (NL), normal skin (NS).

\begin{tabular}{|lllll|}
\hline Dataset & Platform & $\begin{array}{l}\text { No. of } \\
\text { Samples } \\
\text { (LS, NL, } \\
\text { NS) }\end{array}$ & References \\
\hline GSE57178 & $\begin{array}{l}\text { GPL6244 Platforms (Affymetrix Human Gene 1.0 ST } \\
\text { Array) }\end{array}$ & $6,7,5$ & $\begin{array}{l}\text { Patel OP et al. } \\
\text { (2015) }\end{array}$ \\
\hline GSE72540 & $\begin{array}{l}\text { GPL16699 Platforms (Agilent-039494 SurePrint G3 } \\
\text { Human GE v2 8x60K Microarray 039381) }\end{array}$ & $10,13,8$ & $\begin{array}{l}\text { Giménez-Arnau } \\
\text { A et al. (2017) }\end{array}$ \\
\hline
\end{tabular}

Table 2. The top 10 biological processes enriched of DEGs. 


\begin{tabular}{|c|c|c|c|c|}
\hline ID & Term & P-value & Number & Genes \\
\hline GO:0006954 & inflammatory response & 4.74E-05 & 9 & $\begin{array}{l}\text { IL6, CYBB, PTGS2, FPR1, } \\
\text { TLR4, FPR3, FPR2, } \\
\text { CCL18, CD14 }\end{array}$ \\
\hline GO:0050900 & leukocyte migration & $2.32 \mathrm{E}-04$ & 4 & $\begin{array}{l}\text { ICAM1, FPR1, FPR3, } \\
\text { FPR2 }\end{array}$ \\
\hline GO:0007155 & cell adhesion & $2.70 \mathrm{E}-04$ & 7 & $\begin{array}{l}\text { ICAM1, TNFAIP6, ITGAX, } \\
\text { SELL, HAS2, THBS1, } \\
\text { CYR61 }\end{array}$ \\
\hline G0:0043066 & $\begin{array}{l}\text { negative regulation of apoptotic } \\
\text { process }\end{array}$ & $4.90 \mathrm{E}-04$ & 8 & $\begin{array}{l}\text { IL6, SOCS3, HCK, } \\
\text { DNAJA1, PIM1, GREM1, } \\
\text { MYC, CYR61 }\end{array}$ \\
\hline GO:0045084 & $\begin{array}{l}\text { positive regulation of interleukin- } \\
12 \text { biosynthetic process }\end{array}$ & 8.44E-04 & 3 & IRF1, TLR4 \\
\hline G0:0045087 & innate immune response & $9.73 E-04$ & 7 & $\begin{array}{l}\text { CYBB, S100A8, HCK, } \\
\text { S100A9, TLR4, PTX3, } \\
\text { CD14 }\end{array}$ \\
\hline GO:0002430 & $\begin{array}{l}\text { complement receptor mediated } \\
\text { signaling pathway }\end{array}$ & 0.001435 & 3 & FPR1, FPR3, FPR2 \\
\hline GO:0042554 & superoxide anion generation & 0.002173 & 3 & CYBB, NCF2, SOD2 \\
\hline GO:0050729 & $\begin{array}{l}\text { positive regulation of } \\
\text { inflammatory response }\end{array}$ & 0.002306 & 4 & $\begin{array}{l}\text { S100A8, LDLR, S100A9, } \\
\text { CCL18 }\end{array}$ \\
\hline G0:0030593 & neutrophil chemotaxis & 0.004067 & 4 & $\begin{array}{l}\text { S100A8, S100A9, } \\
\text { TREM1, CCL18 }\end{array}$ \\
\hline
\end{tabular}

Table 3. The KEGG pathway analysis of all the DEGs. 


\begin{tabular}{|c|c|c|c|c|}
\hline ID & Term & $\begin{array}{l}\mathrm{P}- \\
\text { value }\end{array}$ & Number & Genes \\
\hline hsa04145 & Phagosome & $\begin{array}{l}4.81 \mathrm{E}- \\
10\end{array}$ & 8 & $\begin{array}{l}\text { MRC1, NCF2, TUBA1C, THBS1, } \\
\text { CYBB, CD14, TLR4, FCGR2A }\end{array}$ \\
\hline hsa05144 & Malaria & $\begin{array}{l}4.43 \mathrm{E}- \\
08\end{array}$ & 5 & IL6, SELE, ICAM1, TLR4, THBS1 \\
\hline hsa04668 & TNF signaling pathway & $\begin{array}{l}7.03 \mathrm{E}- \\
08\end{array}$ & 6 & $\begin{array}{l}\text { PTGS2, IRF1, SOCS3, SELE, IL6, } \\
\text { ICAM1 }\end{array}$ \\
\hline hsa05150 & $\begin{array}{l}\text { Staphylococcus aureus } \\
\text { infection }\end{array}$ & $\begin{array}{l}2.05 \mathrm{E}- \\
07\end{array}$ & 5 & FPR1, FPR2, FPR3, ICAM1, FCGR2A \\
\hline hsa05140 & Leishmaniasis & $\begin{array}{l}3.05 \mathrm{E}- \\
07\end{array}$ & 5 & CYBB, PTGS2, FCGR2A, TLR4, NCF2 \\
\hline hsa04621 & $\begin{array}{l}\text { NOD-like receptor signaling } \\
\text { pathway }\end{array}$ & $\begin{array}{l}9.64 \mathrm{E}- \\
07\end{array}$ & 6 & $\begin{array}{l}\text { IL6, NAMPT, CYBB, IFI16, TLR4, } \\
\text { PANX1 }\end{array}$ \\
\hline hsa05152 & Tuberculosis & $\begin{array}{l}9.95 \mathrm{E}- \\
07\end{array}$ & 6 & $\begin{array}{l}\text { ITGAX, MRC1, FCGR2A, IL6, CD14, } \\
\text { TLR4 }\end{array}$ \\
\hline hsa05167 & $\begin{array}{l}\text { Kaposi sarcoma- } \\
\text { associated herpesvirus } \\
\text { infection }\end{array}$ & $\begin{array}{l}1.24 \mathrm{E}- \\
06\end{array}$ & 6 & $\begin{array}{l}\text { PTGS2, IL6, ZFP36, ICAM1, HCK, } \\
\text { MYC }\end{array}$ \\
\hline hsa04933 & $\begin{array}{l}\text { AGE-RAGE signaling } \\
\text { pathway in diabetic } \\
\text { complications }\end{array}$ & $\begin{array}{l}1.26 \mathrm{E}- \\
06\end{array}$ & 5 & CYBB, SELE, IL6, ICAM1, PIM1 \\
\hline hsa04064 & $\begin{array}{l}\text { NF-kappa B signaling } \\
\text { pathway }\end{array}$ & $\begin{array}{l}1.26 \mathrm{E}- \\
06\end{array}$ & 5 & PTGS2, CD14, CCL13, ICAM1, TLR4 \\
\hline hsa05134 & Legionellosis & $\begin{array}{l}3.76 \mathrm{E}- \\
06\end{array}$ & 4 & IL6, CD14, HSPA8, TLR4 \\
\hline hsa01100 & Metabolic pathways & $\begin{array}{l}9.02 \mathrm{E}- \\
06\end{array}$ & 12 & $\begin{array}{l}\text { PTGS2, ACER1, MTHFD2, CA2, FAP, } \\
\text { UAP1, NAMPT, SRM, PLA2G2A, } \\
\text { NNMT, PNP, GFPT2 }\end{array}$ \\
\hline hsa04630 & $\begin{array}{l}\text { Jak-STAT signaling } \\
\text { pathway }\end{array}$ & $\begin{array}{l}1.22 \mathrm{E}- \\
05\end{array}$ & 5 & IL6, MYC, OSMR, SOCS3, PIM1 \\
\hline hsa05133 & Pertussis & $\begin{array}{l}1.27 \mathrm{E}- \\
05\end{array}$ & 4 & IL6, CD14, IRF1, TLR4 \\
\hline hsa04657 & IL-17 signaling pathway & $\begin{array}{l}2.72 \mathrm{E}- \\
05\end{array}$ & 4 & IL6, PTGS2, S100A9, S100A8 \\
\hline hsa00760 & $\begin{array}{l}\text { Nicotinate and } \\
\text { nicotinamide metabolism }\end{array}$ & $\begin{array}{l}2.75 \mathrm{E}- \\
05\end{array}$ & 3 & PNP, NNMT, NAMPT \\
\hline hsa05143 & African trypanosomiasis & $\begin{array}{l}4.93 \mathrm{E}- \\
05\end{array}$ & 3 & IL6, SELE, ICAM1 \\
\hline hsa04066 & HIF-1 signaling pathway & $4.95 \mathrm{E}-$ & 4 & CYBB, IL6, TIMP1, TLR4 \\
\hline
\end{tabular}


hsa05166 Human T-cell leukemia $\quad$ 4.97E- $5 \quad$ IL6, ETS2, MYC, ZFP36, ICAM1 virus 1 infection 05

hsa04380 Osteoclast differentiation $\quad 9.06 \mathrm{E}-\quad 4$ 05

TYROBP, NCF2, SOCS3, FCGR2A

Table 4. The pathway analysis of all the DEGs via Reactome database. 


\begin{tabular}{|c|c|c|c|c|}
\hline ID & Term & $\begin{array}{l}\mathrm{P}- \\
\text { value }\end{array}$ & Number & Genes \\
\hline $\begin{array}{l}\text { R-HSA- } \\
168256\end{array}$ & Immune System & $\begin{array}{l}1.47 \mathrm{E}- \\
29\end{array}$ & 39 & $\begin{array}{l}\text { PTGS2, MT2A, TIMP1, NCF2, HSPA8, TREM1, } \\
\text { PANX1, CD53, MRC1, TYROBP, PTX3, IFI16, } \\
\text { OSMR, S100A9, S100A8, ICAM1, MYC, } \\
\text { CRISPLD2, FCN1, SELL, PIM1, FPR1, FPR2, } \\
\text { IFI30, FCGR2A, CYBB, SERPINB1, HCK, ITGAX, } \\
\text { PLA2G2A, IRF1, SOCS3, PNP, TNFAIP6, SLC2A3, } \\
\text { IL6, TUBA1C, CD14, TLR4 }\end{array}$ \\
\hline $\begin{array}{l}\text { R-HSA- } \\
168249\end{array}$ & $\begin{array}{l}\text { Innate Immune } \\
\text { System }\end{array}$ & $\begin{array}{l}1.69 \mathrm{E}- \\
22\end{array}$ & 26 & $\begin{array}{l}\text { NCF2, CD 53, HSPA8, TREM1, PANX1, TYROBP, } \\
\text { PTX3, IFI16, S100A9, S100A8, CRISPLD2, FCN1, } \\
\text { SELL, FPR1, FPR2, FCGR2A, PLA2G2A, } \\
\text { SERPINB1, HCK, ITGAX, CYBB, PNP, TNFAIP6, } \\
\text { SLC2A3, CD14, TLR4 }\end{array}$ \\
\hline $\begin{array}{l}\text { R-HSA- } \\
6798695\end{array}$ & $\begin{array}{l}\text { Neutrophil } \\
\text { degranulation }\end{array}$ & $\begin{array}{l}3.55 \mathrm{E}- \\
20\end{array}$ & 19 & $\begin{array}{l}\text { ITGAX, CRISPLD2, FCN1, PTX3, SELL, CD53, } \\
\text { TYROBP, HSPA8, FPR2, TNFAIP6, SLC2A3, } \\
\text { FCGR2A, CYBB, CD14, S100A9, S100A8, FPR1, } \\
\text { SERPINB1, PNP }\end{array}$ \\
\hline $\begin{array}{l}\text { R-HSA- } \\
6785807\end{array}$ & $\begin{array}{l}\text { Interleukin-4 and } \\
\text { Interleukin-13 } \\
\text { signaling }\end{array}$ & $\begin{array}{l}7.65 \mathrm{E}- \\
13\end{array}$ & 9 & $\begin{array}{l}\text { ITGAX, PTGS2, TIMP1, SOCS3, PIM1, HSPA8, } \\
\text { IL6, ICAM1, MYC }\end{array}$ \\
\hline $\begin{array}{l}\text { R-HSA- } \\
1280215\end{array}$ & $\begin{array}{l}\text { Cytokine } \\
\text { Signaling in } \\
\text { Immune system }\end{array}$ & $\begin{array}{l}2.79 \mathrm{E}- \\
11\end{array}$ & 15 & $\begin{array}{l}\text { ITGAX, PTGS2, IRF1, MT2A, TIMP1, SOCS3, } \\
\text { PIM1, FPR1, HSPA8, IFI30, IL6, OSMR, ICAM1, } \\
\text { HCK, MYC }\end{array}$ \\
\hline $\begin{array}{l}\text { R-HSA- } \\
449147\end{array}$ & $\begin{array}{l}\text { Signaling by } \\
\text { Interleukins }\end{array}$ & $\begin{array}{l}1.31 \mathrm{E}- \\
09\end{array}$ & 12 & $\begin{array}{l}\text { ITGAX, PTGS2, TIMP1, SOCS3, PIM1, FPR1, } \\
\text { HSPA8, IL6, OSMR, ICAM1, HCK, MYC }\end{array}$ \\
\hline $\begin{array}{l}\text { R-HSA- } \\
196854\end{array}$ & $\begin{array}{l}\text { Metabolism of } \\
\text { vitamins and } \\
\text { cofactors }\end{array}$ & $\begin{array}{l}2.21 \mathrm{E}- \\
09\end{array}$ & 8 & $\begin{array}{l}\text { PTGS2, MTHFD2, VNN2, SLC2A3, NAMPT, } \\
\text { LDLR, NNMT, SLC5A6 }\end{array}$ \\
\hline $\begin{array}{l}\text { R-HSA- } \\
8953897\end{array}$ & $\begin{array}{l}\text { Cellular } \\
\text { responses to } \\
\text { external stimuli }\end{array}$ & $\begin{array}{l}2.55 \mathrm{E}- \\
09\end{array}$ & 11 & $\begin{array}{l}\text { NCF2, DNAJA1, MT2A, HSPH1, MT1M, TUBA1C, } \\
\text { HSPA8, CYBB, IL6, ETS2, MT1A }\end{array}$ \\
\hline $\begin{array}{l}\text { R-HSA- } \\
196849\end{array}$ & $\begin{array}{l}\text { Metabolism of } \\
\text { water-soluble } \\
\text { vitamins and } \\
\text { cofactors }\end{array}$ & $\begin{array}{l}3.10 \mathrm{E}- \\
09\end{array}$ & 7 & $\begin{array}{l}\text { PTGS2, MTHFD2, VNN2, SLC2A3, NAMPT, } \\
\text { NNMT, SLC5A6 }\end{array}$ \\
\hline $\begin{array}{l}\text { R-HSA- } \\
1280218\end{array}$ & $\begin{array}{l}\text { Adaptive } \\
\text { Immune System }\end{array}$ & $\begin{array}{l}1.04 \mathrm{E}- \\
08\end{array}$ & 12 & $\begin{array}{l}\text { SELL, NCF2, TLR4, SOCS3, MRC1, TYROBP, } \\
\text { IFI30, CYBB, TUBA1C, CD14, TREM1, ICAM1 }\end{array}$ \\
\hline $\begin{array}{l}\text { R-HSA- } \\
6783783\end{array}$ & $\begin{array}{l}\text { Interleukin-10 } \\
\text { signaling }\end{array}$ & $\begin{array}{l}3.65 \mathrm{E}- \\
08\end{array}$ & 5 & IL6, PTGS2, TIMP1, ICAM1, FPR1 \\
\hline $\begin{array}{l}\text { R-HSA- } \\
5686938\end{array}$ & $\begin{array}{l}\text { Regulation of } \\
\text { TLR by } \\
\text { endogenous } \\
\text { ligand }\end{array}$ & $\begin{array}{l}7.69 \mathrm{E}- \\
08\end{array}$ & 4 & CD14, S100A9, S100A8, TLR4 \\
\hline $\begin{array}{l}\text { R-HSA- } \\
5668599\end{array}$ & $\begin{array}{l}\text { RHO GTPases } \\
\text { Activate NADPH }\end{array}$ & $\begin{array}{l}1.77 \mathrm{E}- \\
07\end{array}$ & 4 & CYBB, NCF2, S100A9, S100A8 \\
\hline
\end{tabular}




\begin{tabular}{|c|c|c|c|c|}
\hline & Oxidases & & & \\
\hline $\begin{array}{l}\text { R-HSA- } \\
444473\end{array}$ & $\begin{array}{l}\text { Formyl peptide } \\
\text { receptors bind } \\
\text { formyl peptides } \\
\text { and many other } \\
\text { ligands }\end{array}$ & $\begin{array}{l}6.23 \mathrm{E}- \\
07\end{array}$ & 3 & FPR1, FPR2, FPR3 \\
\hline $\begin{array}{l}\text { R-HSA- } \\
1430728\end{array}$ & Metabolism & $\begin{array}{l}7.35 \mathrm{E}- \\
07\end{array}$ & 16 & $\begin{array}{l}\text { PTGS2, ACER1, MTHFD2, NNMT, VNN2, CA2, } \\
\text { SLC2A3, NAMPT, SRM, PLA2G2A, LDLR, } \\
\text { ALOX5AP, SLC5A6, PNP, HAS2, CH25H }\end{array}$ \\
\hline $\begin{array}{l}\text { R-HSA- } \\
877300\end{array}$ & $\begin{array}{l}\text { Interferon } \\
\text { gamma } \\
\text { signaling }\end{array}$ & $\begin{array}{l}7.67 \mathrm{E}- \\
07\end{array}$ & 5 & IRF1, SOCS3, MT2A, IFI30, ICAM1 \\
\hline $\begin{array}{l}\text { R-HSA- } \\
2262752\end{array}$ & $\begin{array}{l}\text { Cellular } \\
\text { responses to } \\
\text { stress }\end{array}$ & $\begin{array}{l}9.95 \mathrm{E}- \\
07\end{array}$ & 8 & $\begin{array}{l}\text { NCF2, DNAJA1, HSPH1, TUBA1C, HSPA8, CYBB, } \\
\text { IL6, ETS2 }\end{array}$ \\
\hline $\begin{array}{l}\text { R-HSA- } \\
1236975\end{array}$ & $\begin{array}{l}\text { Antigen } \\
\text { processing- } \\
\text { Cross } \\
\text { presentation }\end{array}$ & $\begin{array}{l}1.15 \mathrm{E}- \\
06\end{array}$ & 5 & CYBB, NCF2, CD14, TLR4, MRC1 \\
\hline $\begin{array}{l}\text { R-HSA- } \\
109582\end{array}$ & Hemostasis & $\begin{array}{l}1.71 \mathrm{E}- \\
06\end{array}$ & 9 & $\begin{array}{l}\text { ITGAX, SELL, IRF1, TIMP1, TUBA1C, SELE, } \\
\text { THBS1, TREM1, SERPINE2 }\end{array}$ \\
\hline $\begin{array}{l}\text { R-HSA- } \\
5661231\end{array}$ & $\begin{array}{l}\text { Metallothioneins } \\
\text { bind metals }\end{array}$ & $\begin{array}{l}9.06 \mathrm{E}- \\
05\end{array}$ & 3 & MT1M, MT2A, MT1A \\
\hline
\end{tabular}

\section{Figures}


A

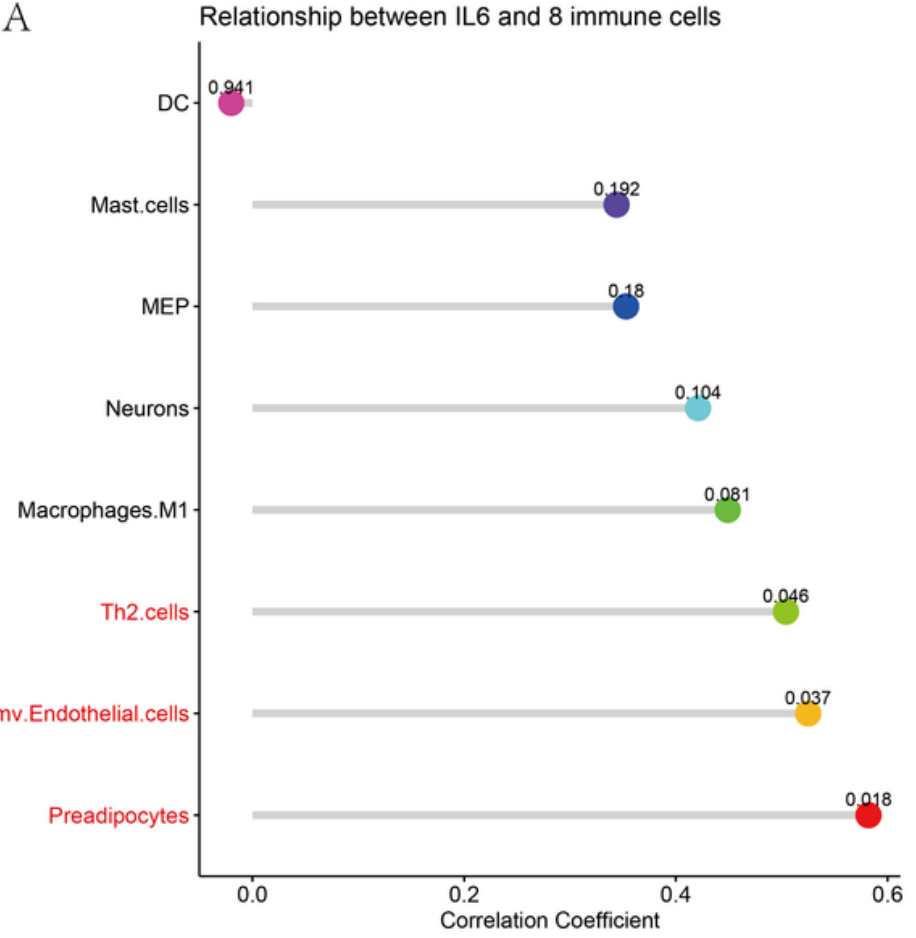

C

Relationship between ICAM1 and 8 immune cells

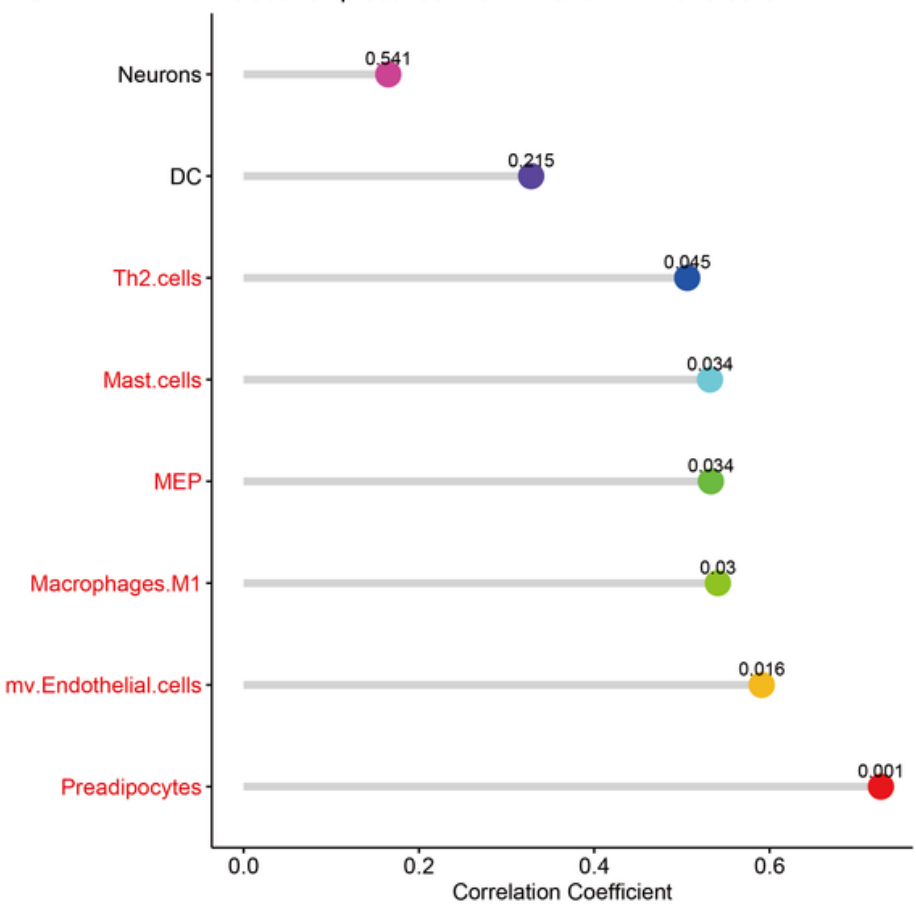

B

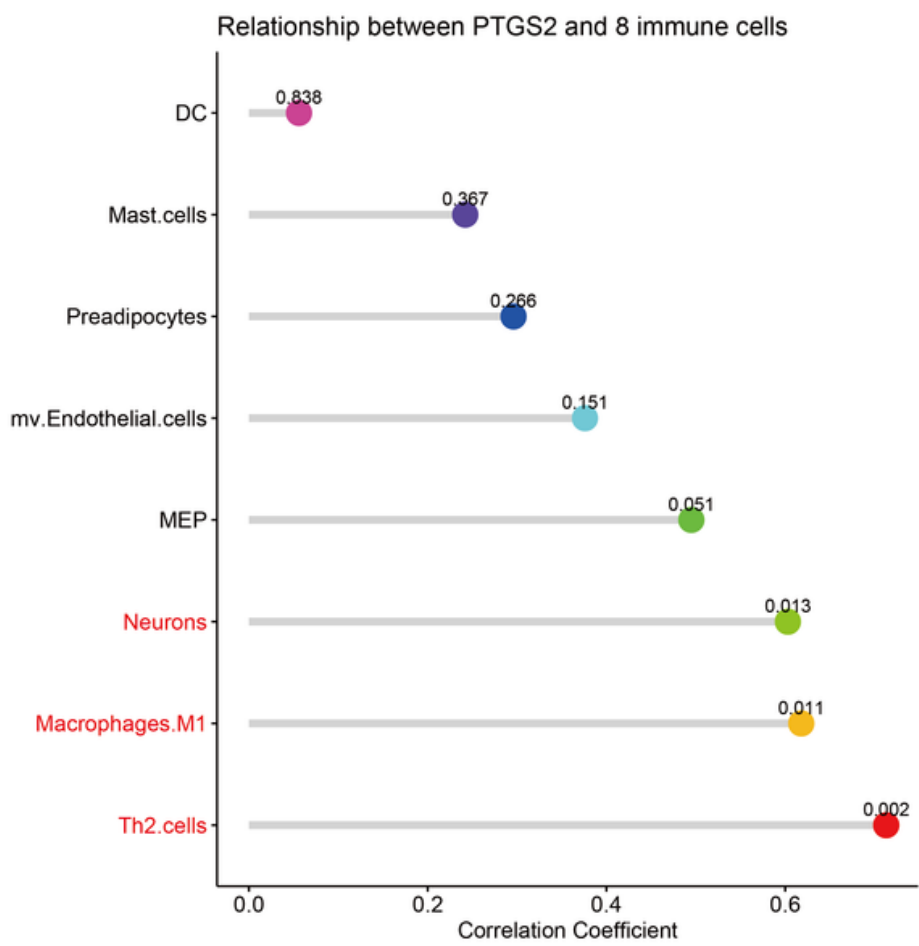

D

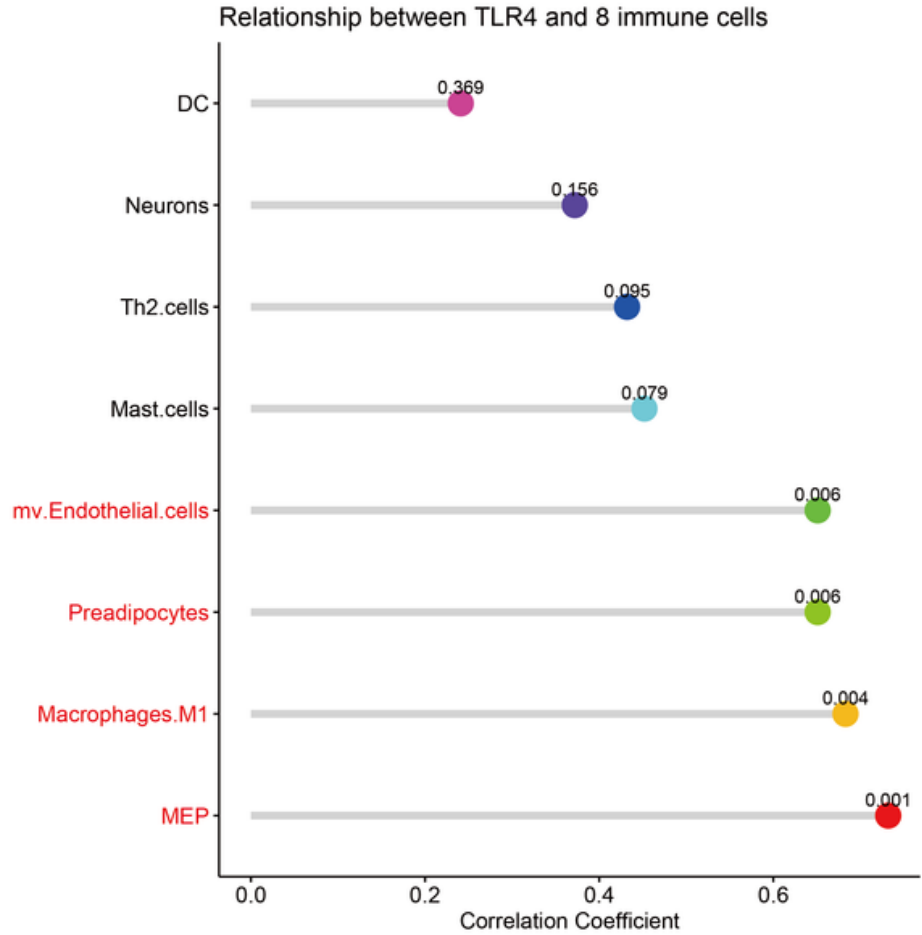

\section{Figure 1}

Correlation between IL6, TLR4, ICAM1, PTGS2 and infiltrating immune cells. The abscissa represents the strength of the association between genes and immune cells; the dots represents the P-value. P-value $<0.05$ was considered significant. 

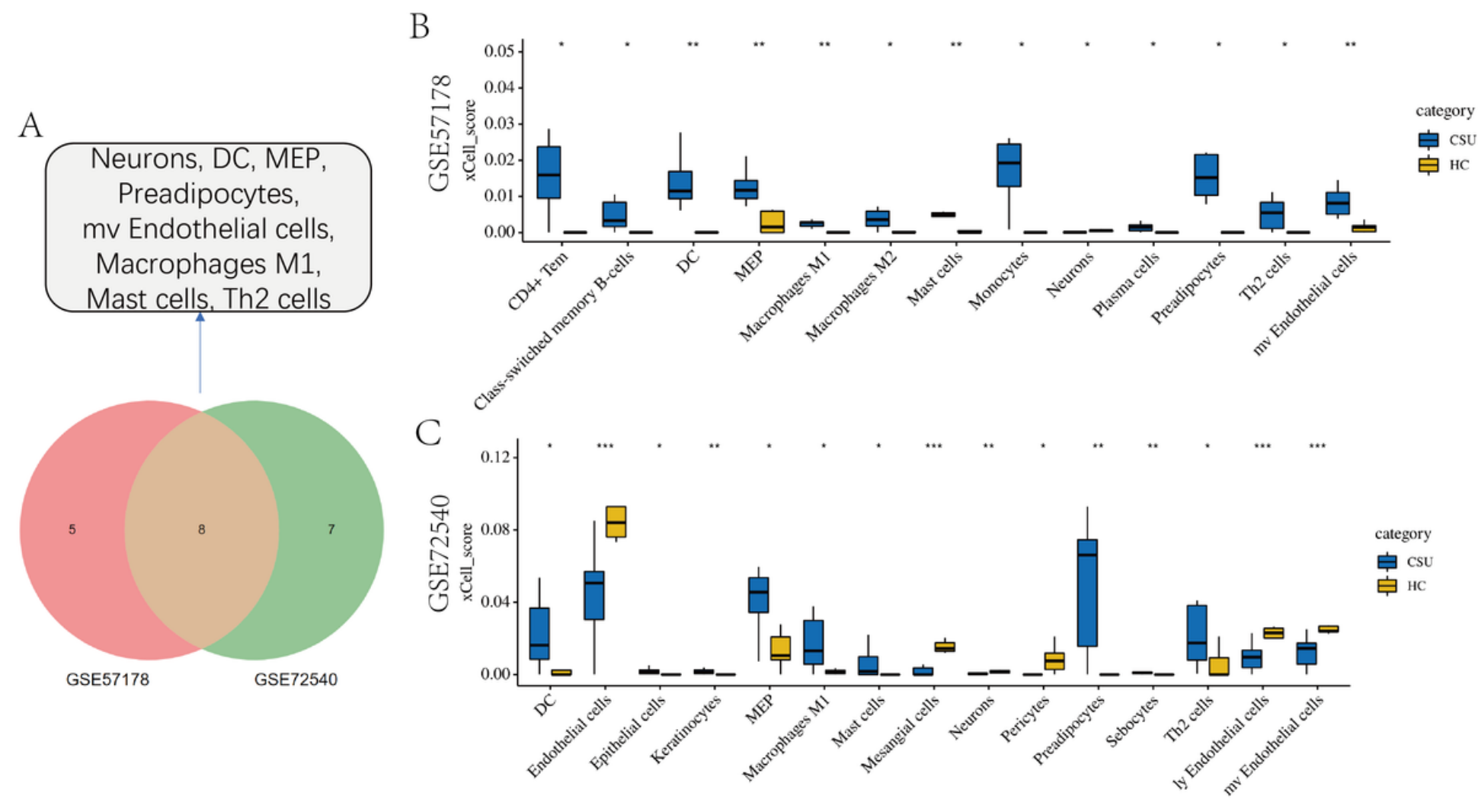

Figure 2

Evaluation and visualization of immune cell infiltration. (A) Differential cell types common to the GSE57178 and GSE72540 dataset. (B) xCell scores of 64 cell types between HC and CSU in the GSE57178 and GSE72540 dataset. P-value $<0.05$ was considered significant. 

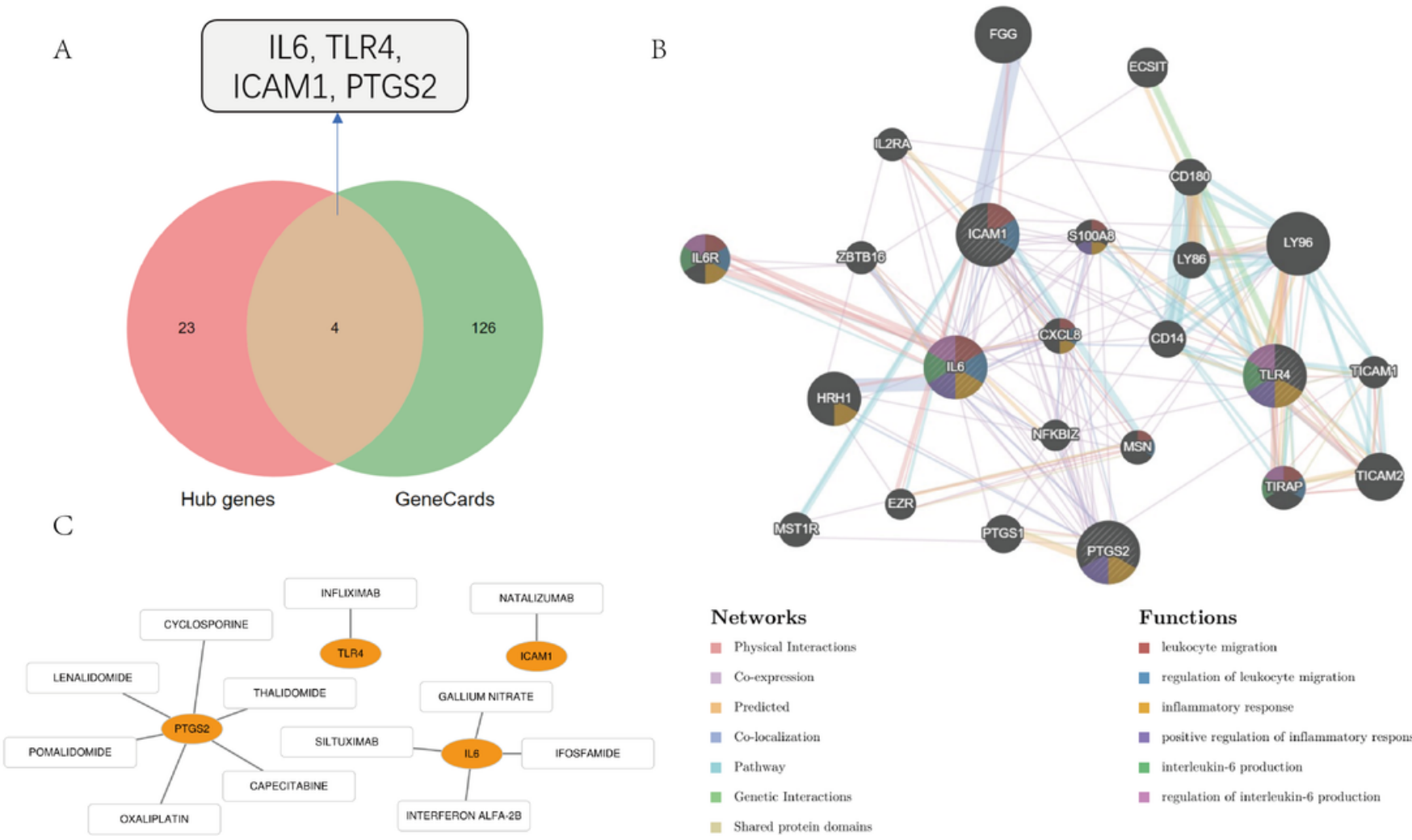

Functions

a leukocyte migration

- regulation of leukocyte migration

[n inflammatory response

a positive regulation of inflammatory response

anterleukin-6 production

an regulation of interleukin-6 production

\section{Figure 3}

(A) Venn diagram of hub genes (degrees $\geq 10$ ) and potential genes related to CSU (Relevance score $\geq 20$ ). (B) Key genes and their co-expression genes were analyzed using GeneMANIA. (C) Drug-gene interaction diagram, yellow circle indicates the differentially expressed gene and blank square indicates the drug. 
A

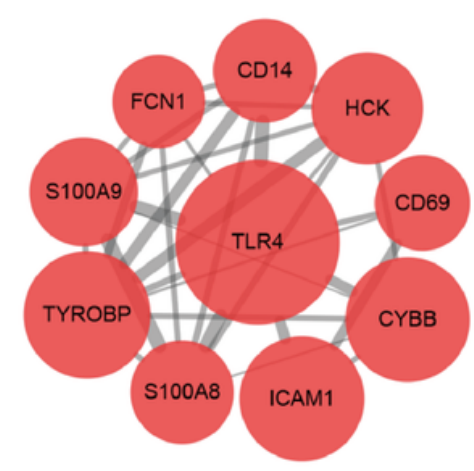

C

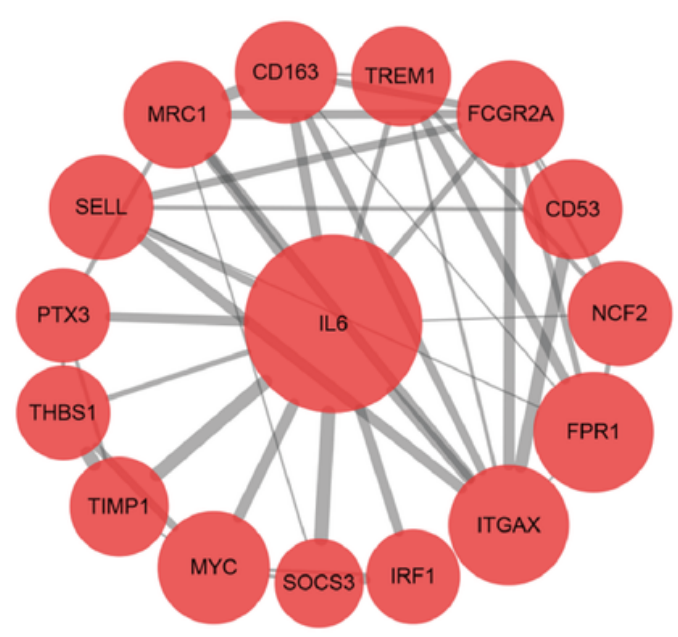

$\mathrm{B}$

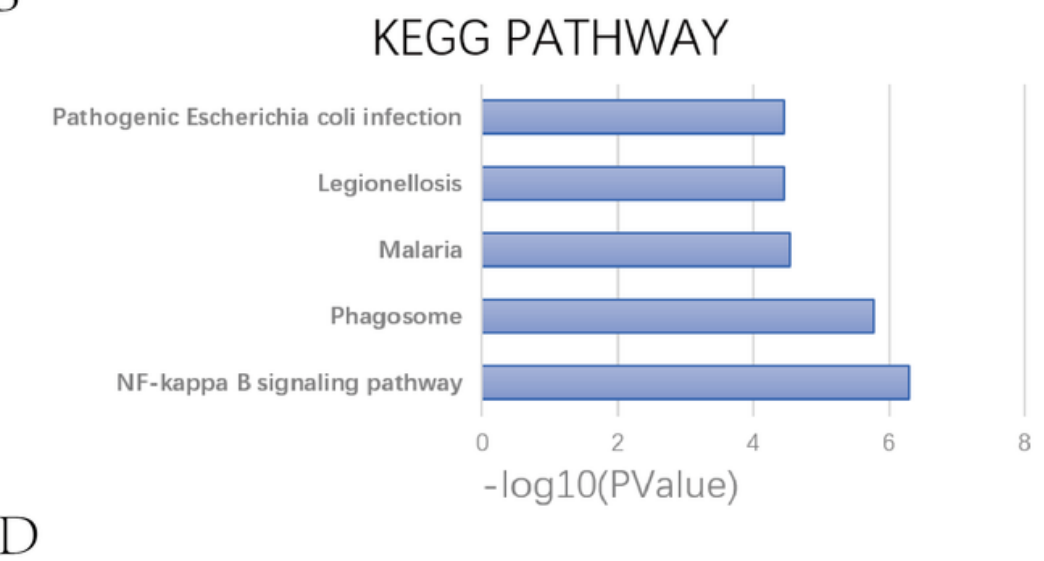

KEGG PATHWAY

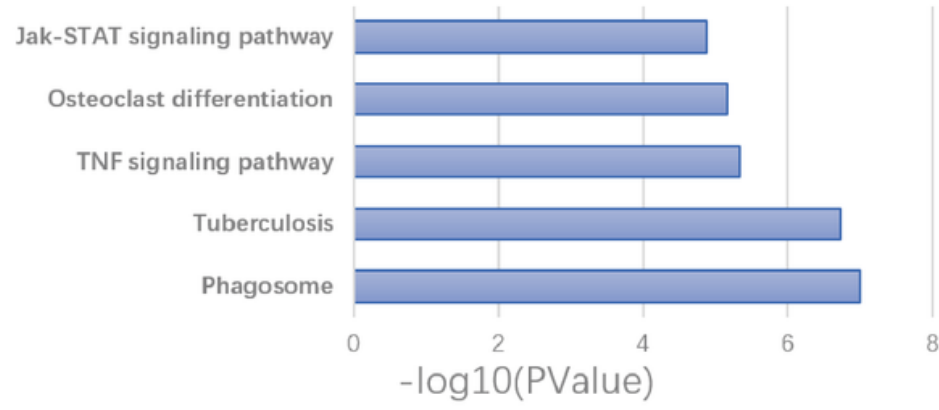

Figure 4

The KEGG pathway analysis of the genes included in each subnetwork. (A-B) Module 1 and the pathway enrichment analysis of genes in module 1. (C-D) Module 2 and the pathway enrichment analysis of genes in module 2. P-value $<0.05$ was considered significant. 
A

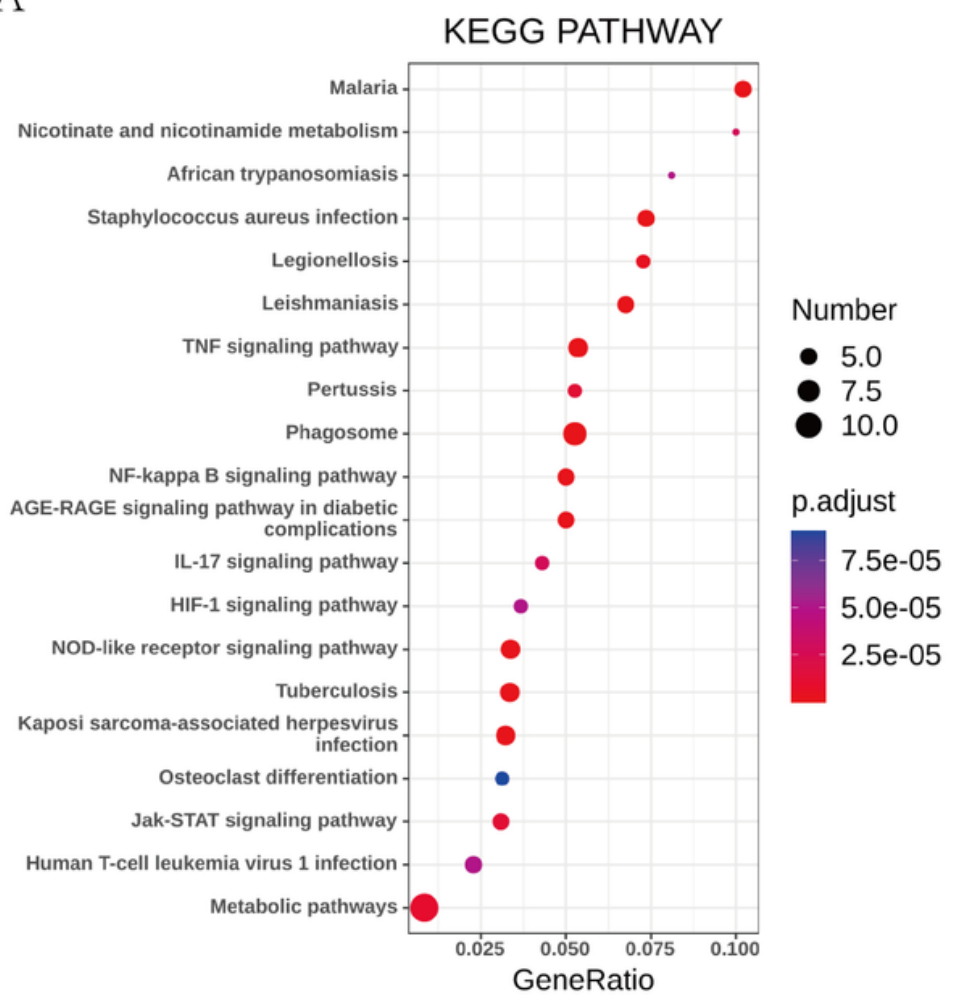

B

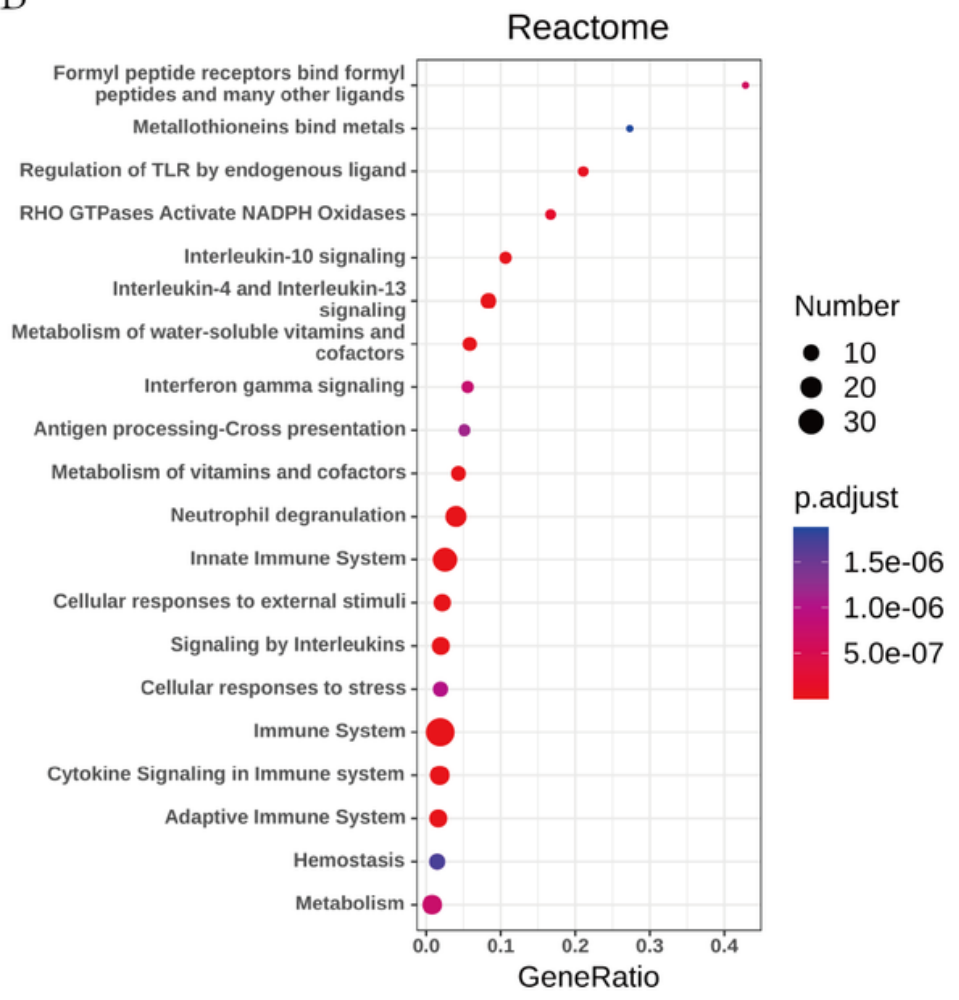

Figure 5

The pathway analysis of DEGs by KOBAS 3.0. (A) The KEGG pathway analysis of all the DEGs. (B) The pathway analysis of all the DEGs via Reactome database. P-value $<0.05$ was considered significant.

percentage $\longrightarrow-\log 10$ ( $p$-value) $\rightarrow-p=0.05$ reference

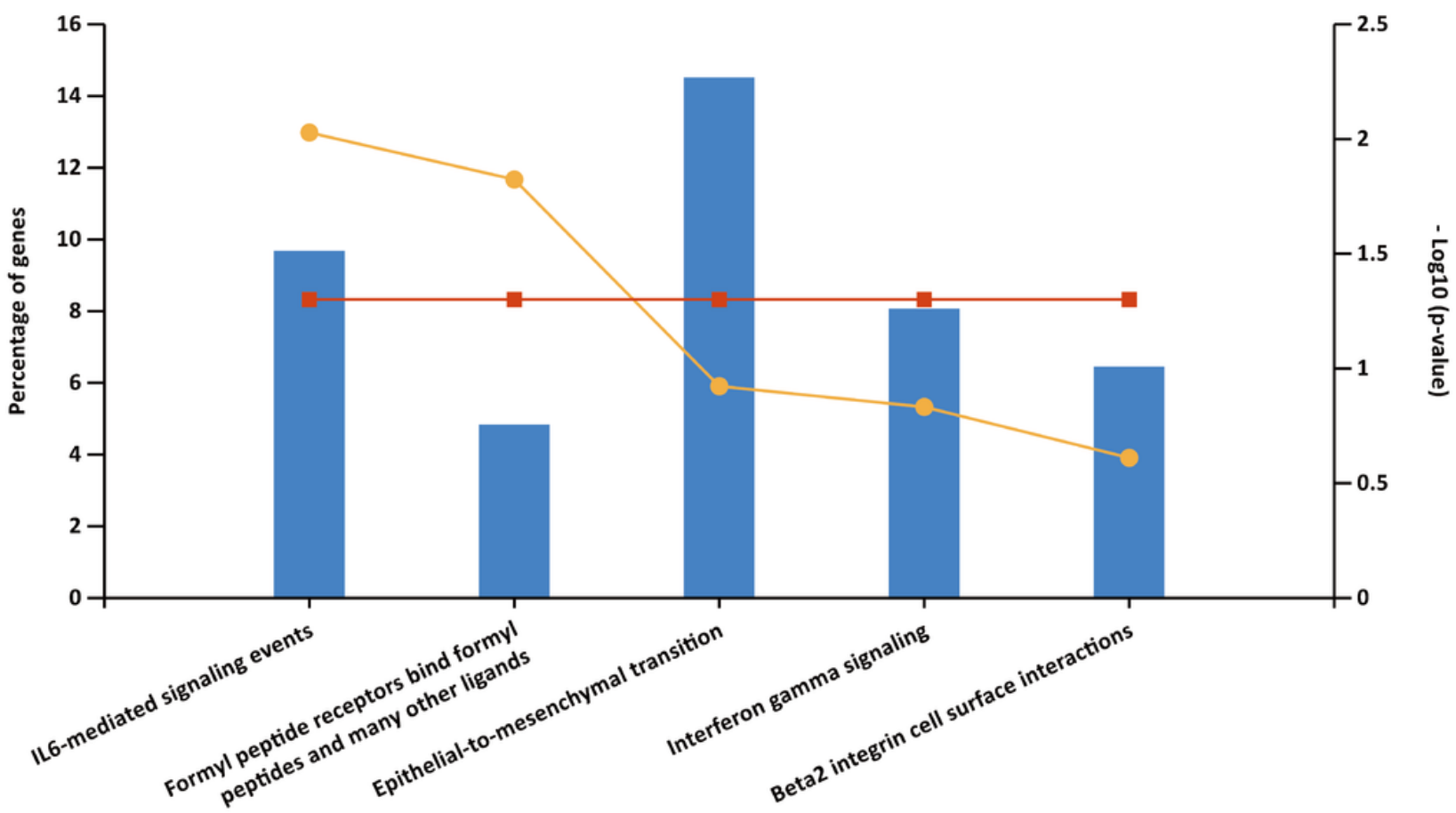

Biological pathway 


\section{Figure 6}

The biological pathways of DEGs by Funrich. P-value $<0.05$ was considered significant.

A

Biological Processes (BP)

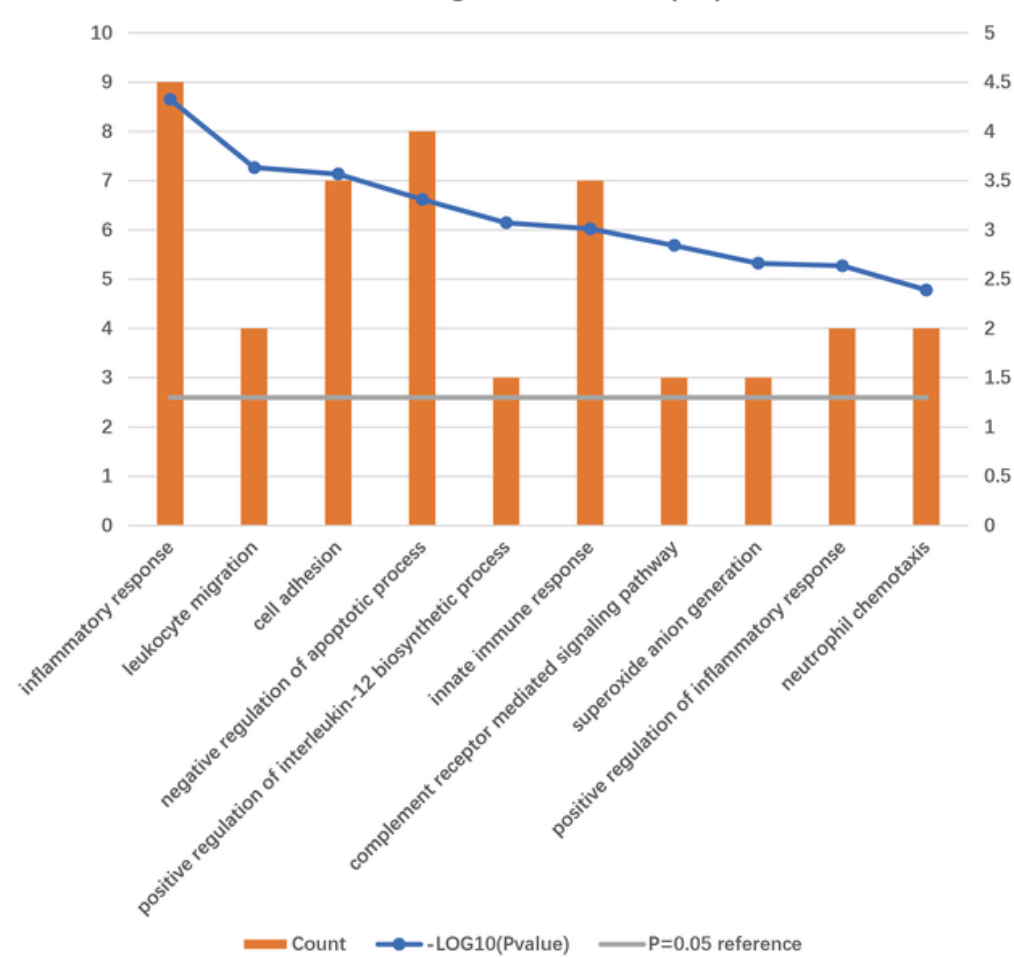

B

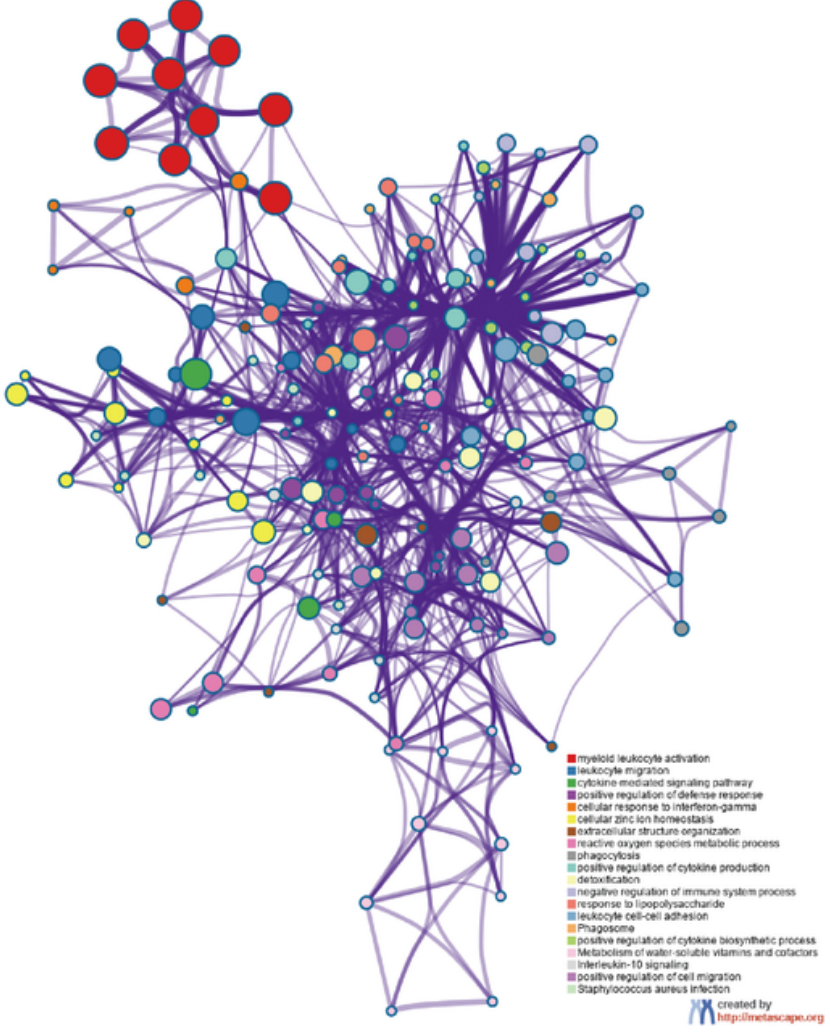

Figure 7

(A) Top 10 BP were selected and shown in bar chart according to adj. P-value. (B) Metascape visualizes the interactive network of BP. P-value $<0.05$ was considered significant.
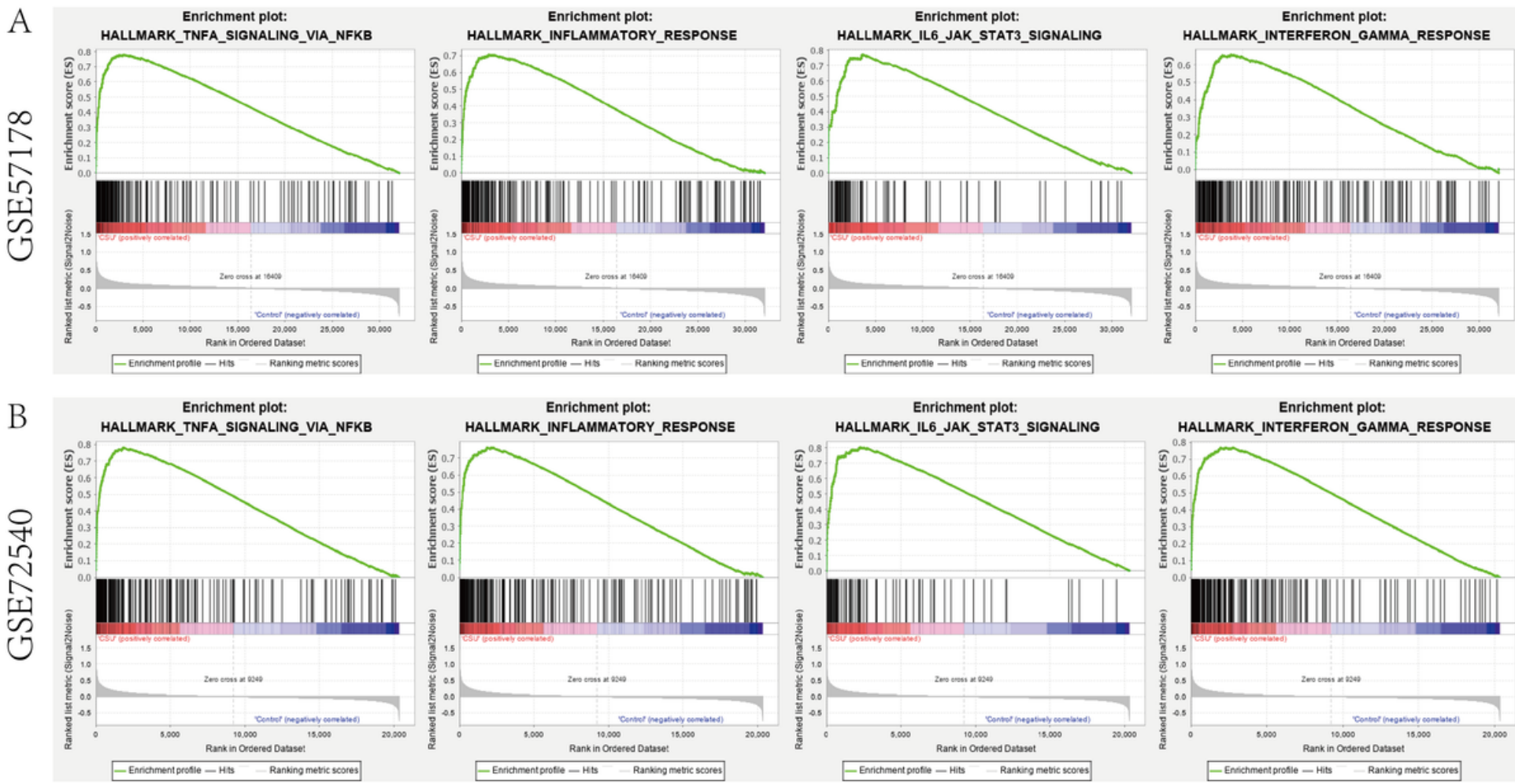


\section{Figure 8}

h.all.v 6.2.symbols.gmt [Hallmarks] gene set database was used to analyse the whole gene expression value of the CSU and healthy controls samples. GSEA first filtered the gene set according to the number of genes contained in the gene set, with the minimum number of 15 genes and the maximum number of 500 genes by default. Significant gene sets were cut-off by FDR $<0.25$ and P-value $<0.05$.

A

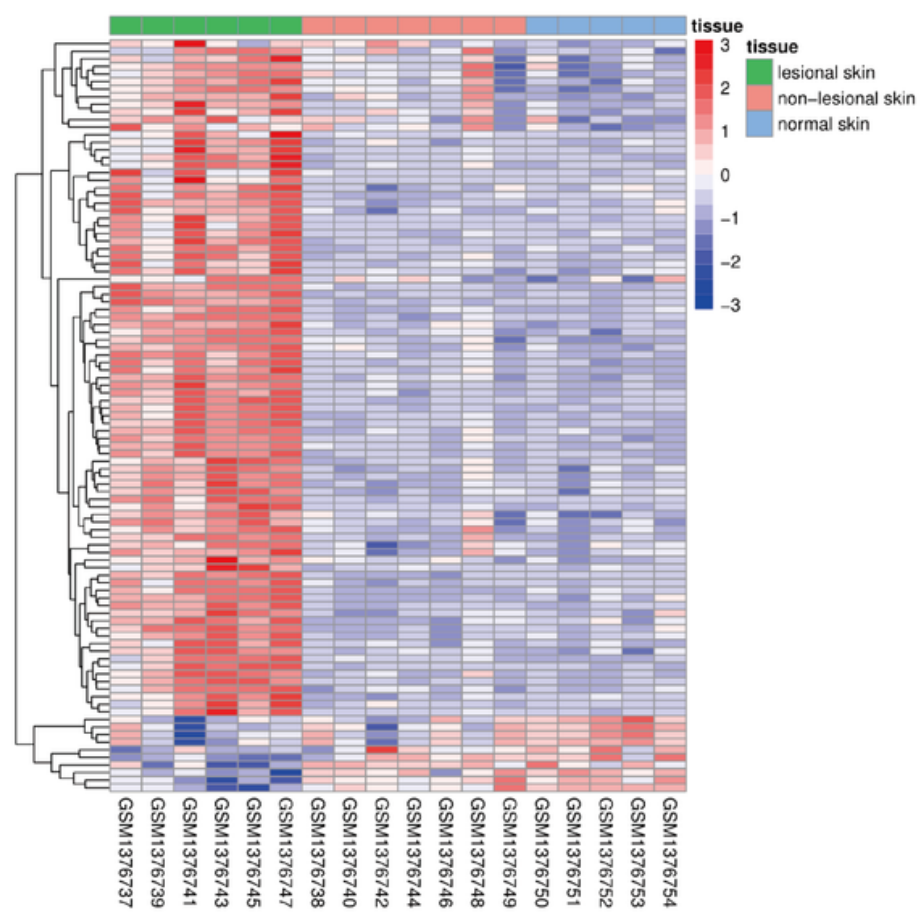

$\mathrm{B}$

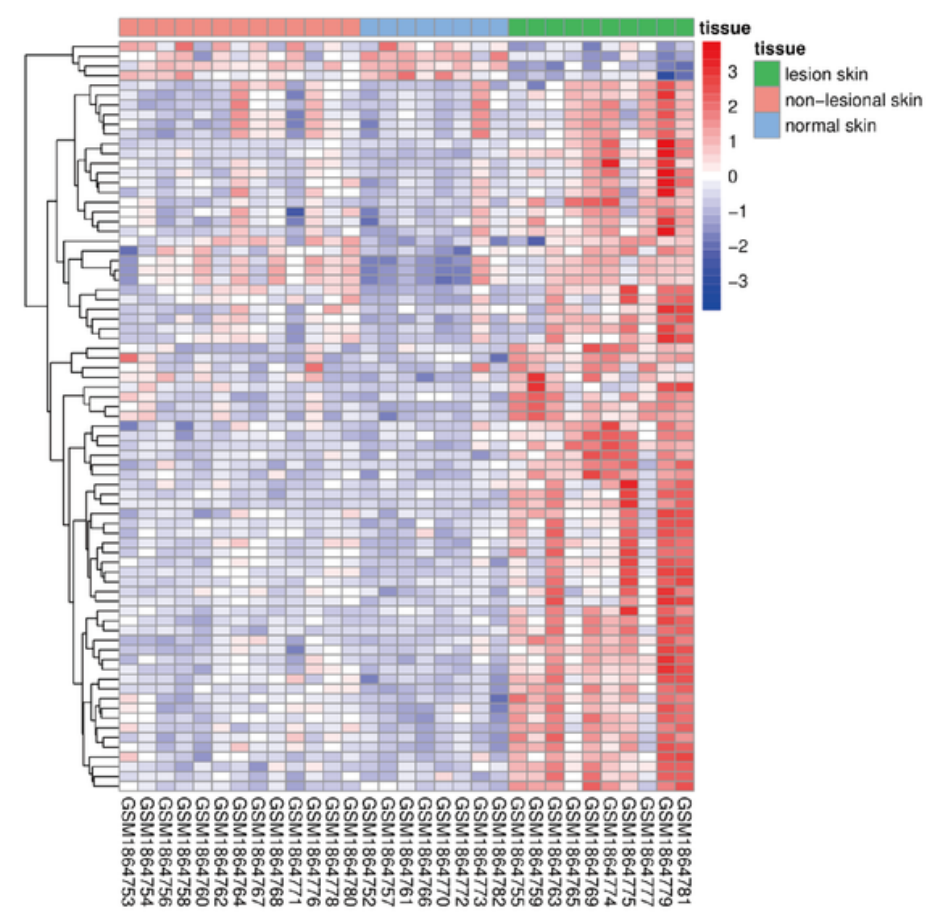

\section{Figure 9}

A-B were heat maps of DEGs. Among them, red indicates up-regulated genes and blue indicates downregulated genes. White indicates no differential expression. 
A

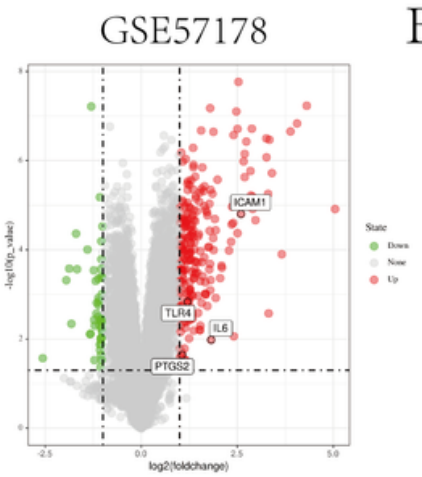

B

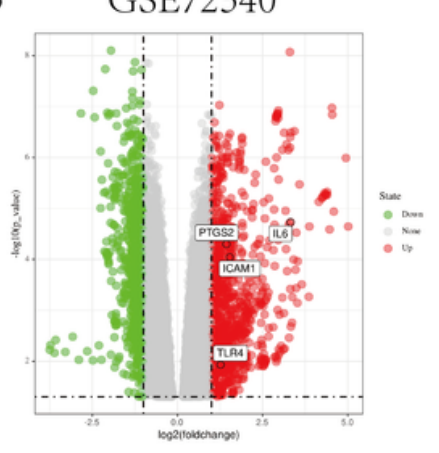

C

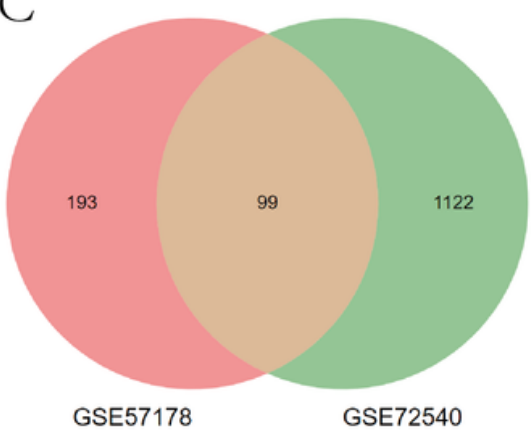

$\mathrm{D}$

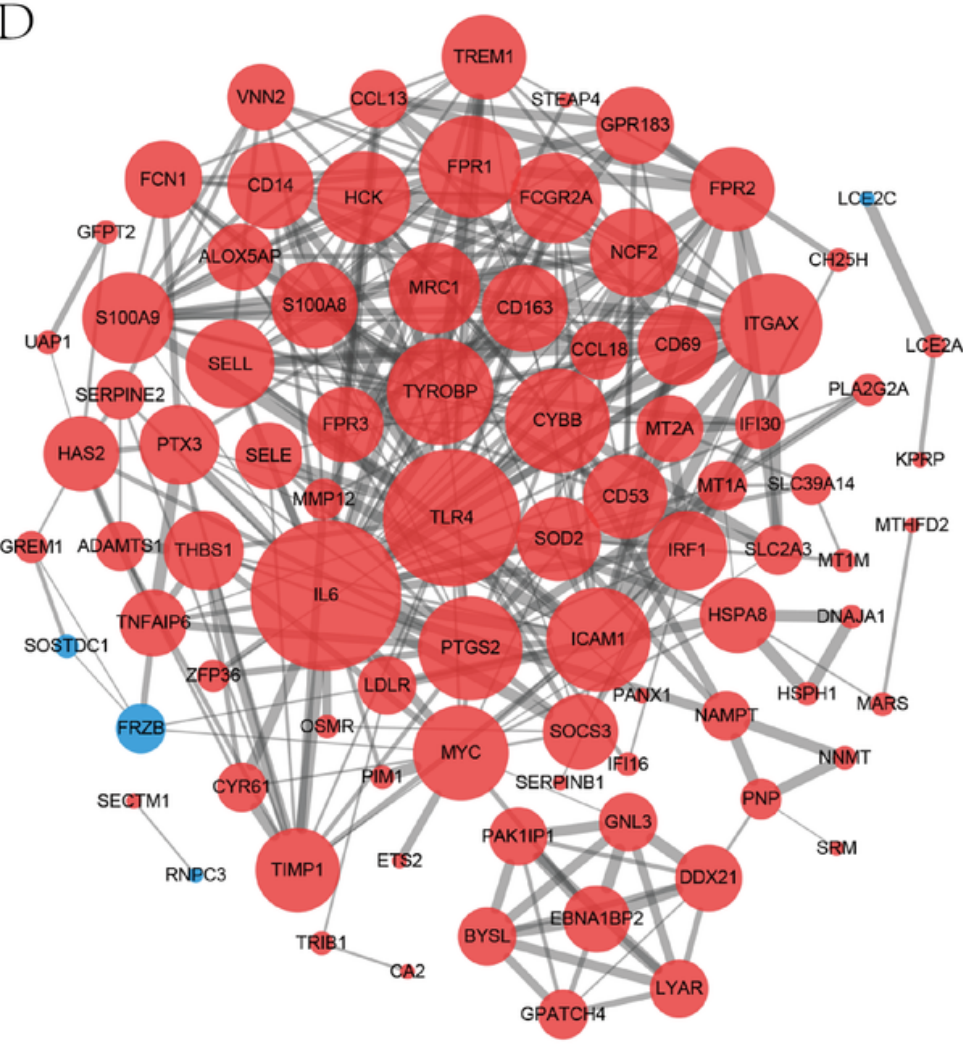

\section{Figure 10}

Volcano figure, Venn diagram, PPI network of DEGs. (A-B) Volcano figure of DEGs. Among them, red indicates up-regulated genes and green indicates down-regulated genes. Black indicates no differential expression. (C) DEGs were selected with a fold change $>1$ and P-value $<0.05$ among the mRNA expression profiling sets GSE57178 and GSE72540. The 2 datasets showed an overlap of 99 genes. (D) The PPI network of DEGs was constructed using Cytoscape. Upregulated genes are marked in light red; downregulated genes are marked in light blue.

\section{Supplementary Files}

This is a list of supplementary files associated with this preprint. Click to download.

- tables1.docx 